Review

\title{
Sulfur-Functionalized $N$-Heterocyclic Carbene Complexes of Pd(II): Syntheses, Structures and Catalytic Activities
}

\section{Dan Yuan and Han Vinh Huynh *}

Department of Chemistry, 3 Science Drive 3, National University of Singapore, 117543, Singapore; E-Mail: g0700466@ nus.edu.sg

* Author to whom correspondence should be addressed; E-Mail: chmhhv@ nus.edu.sg;

Tel.: +65-6516-2670; Fax: +65-6779-1691.

Received: 1 February 2012; in revised form: 20 February 2012 / Accepted: 23 February 2012 /

Published: 1 March 2012

\begin{abstract}
N-heterocyclic carbenes (NHCs) can be easily modified by introducing functional groups at the nitrogen atoms, which leads to versatile coordination chemistry as well as diverse catalytic applications of the resulting complexes. This article summarizes our contributions to the field of NHCs bearing different types of sulfur functions, i.e., thioether, sulfoxide, thiophene, and thiolato. The experimental evidence for the truly hemilabile coordination behavior of a Pd(II) thioether-NHC complex has been reported as well. In addition, complexes bearing rigid CSC-pincer ligands have been synthesized and the reasons for pincer versus pseudo-pincer formation investigated. Incorporation of the electron-rich thiolato function resulted in the isolation of structurally diverse complexes. The catalytic activities of selected complexes have been tested in Suzuki-Miyaura, Mizoroki-Heck and hydroamination reactions.
\end{abstract}

Keywords: N-heterocyclic carbenes; sulfur functions; Pd(II) complexes; catalysis

\section{Introduction}

$\mathrm{N}$-heterocyclic carbenes (NHCs) are nowadays ubiquitous ligands in organometallic chemistry as well as catalysis due to their unique properties [1]. Being strong $\sigma$-donors and generally weak $\pi$-acceptors, NHCs in general form strong bonds with varieties of metal centers, which results in highly stable complexes. Moreover, both steric and electronic properties of NHCs can be conveniently tuned by changing the substituents and backbones, which also contributes to their popularity. 
Modification of NHCs can be easily achieved by introducing functional groups at the nitrogen atoms [2-4]. Donor-functionalized NHCs are potentially polydentate ligands, which can give rise to complexes with enhanced stability through ligand chelation. Varieties of functionalized NHC complexes bearing bidentate chelating NHCs, tripodal NHCs and pincer-type NHCs have been reported and tested in catalysis [2-4]. Since carbenes form strong M-C bonds (vide supra), the presence of other donors that form weaker bonds with metal centers makes these polydentate ligands potentially hemilabile. The concept of hemilability has become important in catalyst design as hemilabile ligands have the ability to provide free coordination sites for substrate activation at the metal center during catalysis, or to stabilize catalytically active species [5].

While NHCs with N, O or P donors are relatively common [2-4], those with sulfur donors still remain relatively unexplored. The sulfur atom exhibits different oxidation states ranging from -2 to +6 , which enriches the already versatile NHC chemistry. NHCs with sulfur functions can be mainly categorized into thioether-NHC, thiolato-NHC, sulfonate-NHC, thiophene-NHC, and sulfoxide-NHC (Figure 1) [6]. In this review, we will describe our contribution to the preparation of NHC Pd(II) complexes with different sulfur functions, their structures and catalytic applications.

Figure 1. NHCs with different sulfur functions.

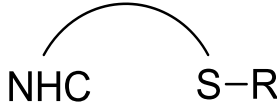

thioether-NHC

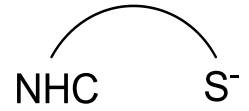

thiolato-NHC

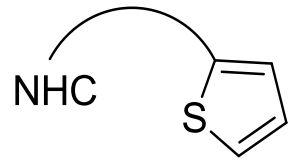

thiophene-NHC

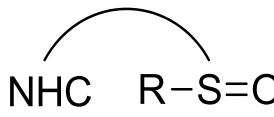

sulfoxide-NHC

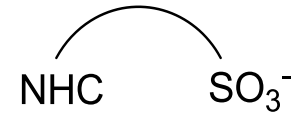

sulfonate-NHC

\section{Sulfur-Functionalized Azolium Salts}

Azolium salts bearing a range of sulfur-functions, i.e., thioether [7-10], sulfoxide [9], thioester [11,12], thiol [11], and thiophene [13], have been synthesized as precursors to S-functionalized NHC complexes.

\subsection{Thioether-Functionalized Azolium Salts}

The alkyl-aryl thioether functionalized imidazolium $\left({ }^{\mathrm{I}} \mathbf{E}_{\mathbf{a} / \mathbf{b}} \cdot \mathrm{HBr}\right)$ and benzimidazolium $\left({ }^{\mathrm{B}} \mathbf{F}_{\mathbf{a} / \mathbf{b}} \cdot \mathrm{HBr}\right)$ salts were synthesized in a five-step sequence (Scheme 1) [7,8]. Commercially available thiosalicyclic acid was treated with alkyl bromides to form the 2-alkylmercaptobenzoic acids $\mathbf{A}_{\mathbf{a} / \mathbf{b}}$. Subsequent esterification of $\mathbf{A}_{\mathbf{a} / \mathbf{b}}$ in $\mathrm{MeOH}$ in the presence of $\mathrm{H}_{2} \mathrm{SO}_{4}$ yielded the mercaptobenzoates $\mathbf{B}_{\mathrm{a} / \mathbf{b}}$, which were reduced with $\mathrm{LiAlH}_{4}$ under anhydrous conditions and acidified to afford the alcohols $\mathbf{C}_{\mathbf{a} / \mathbf{b}}$. The benzyl bromides $\mathbf{D}_{\mathbf{a} / \mathbf{b}}$ were eventually obtained from the substitution reaction of $\mathbf{C}_{\mathbf{a} / \mathbf{b}}$ with $\mathrm{PBr}_{3}$. $\mathrm{N}$-alkylation of $\mathrm{N}$-methylimidazole and $\mathrm{N}$-methylbenzimidazole gave rise to the respective thioether functionalized carbene precursors in overall yields of $63 \%\left({ }^{\mathrm{I}} \mathbf{E}_{\mathbf{a}} \cdot \mathrm{HBr}\right), 64 \%\left({ }^{\mathrm{I}} \mathbf{E}_{\mathbf{b}} \cdot \mathrm{HBr}\right), 57 \%\left({ }^{\mathrm{B}} \mathbf{F}_{\mathbf{a}} \cdot \mathrm{HBr}\right)$, and $59 \%\left({ }^{\mathrm{B}} \mathbf{F}_{\mathbf{b}} \cdot \mathrm{HBr}\right)$ over five steps. 
Scheme 1. Syntheses of alkyl-aryl thioether-functionalized azolium salts $[7,8]$.

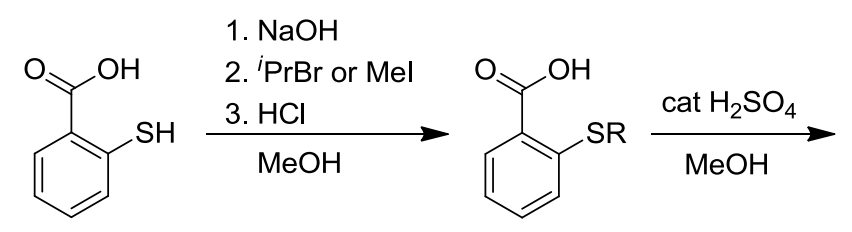<smiles>[R]c1ccccc1C(=O)OC</smiles>

$$
\begin{array}{ll}
\mathbf{A}_{\mathbf{a}}: \mathrm{R}=\operatorname{Me}(95 \%) & \mathbf{B}_{\mathbf{a}}: \mathrm{R}=\mathrm{Me}(92 \%) \\
\mathbf{A}_{\mathbf{b}}: \mathrm{R}={ }^{i} \operatorname{Pr}(99 \%) & \mathbf{B}_{\mathbf{b}}: \mathrm{R}={ }^{i} \operatorname{Pr}(90 \%) \\
& \downarrow \begin{array}{l}
\text { 1. } \mathrm{LiAlH}_{4} / \mathrm{THF} \\
\text { 2. } \mathrm{H}_{2} \mathrm{SO}_{4}
\end{array}
\end{array}
$$
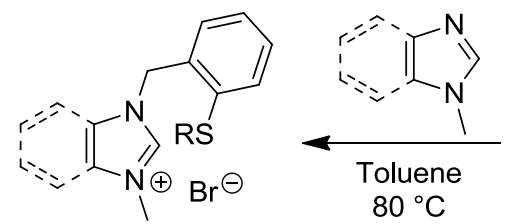<smiles>[R]c1ccccc1CBr</smiles><smiles>CCCCCOCC</smiles>

${ }^{\prime} E_{a} \cdot H B r: R=M e(77 \%)$

$$
D_{\mathrm{a}}: \mathrm{R}=\mathrm{Me}(96 \%)
$$

$\mathbf{D}_{\mathbf{b}}: \mathbf{R}={ }^{i} \operatorname{Pr}(97 \%)$<smiles>[R]c1ccccc1CO</smiles>

${ }^{\prime} \mathbf{E}_{\mathbf{b}} \cdot \mathrm{HBr}: \mathrm{R}={ }^{i} \operatorname{Pr}(79 \%)$

${ }^{B} F_{a} \cdot H B r: R=\operatorname{Me}(70 \%)$

${ }^{\mathrm{B}} \mathrm{F}_{\mathrm{b}} \cdot \mathrm{HBr}: \mathrm{R}={ }^{i} \operatorname{Pr}(70 \%)$

$C_{\mathrm{a}}: \mathrm{R}=\operatorname{Me}(97 \%)$

$\mathrm{C}_{\mathrm{b}}: \mathrm{R}={ }^{i} \operatorname{Pr}(97 \%)$

\subsection{Thioether-Bridged Diazolium Salts}

The alkyl-alkyl thioether-bridged diazolium salts, on the other hand, were synthesized in a different approach (Scheme 2) [9,10].

Scheme 2. Syntheses of thioether/sulfoxide-bridged azolium salts $[9,10]$.

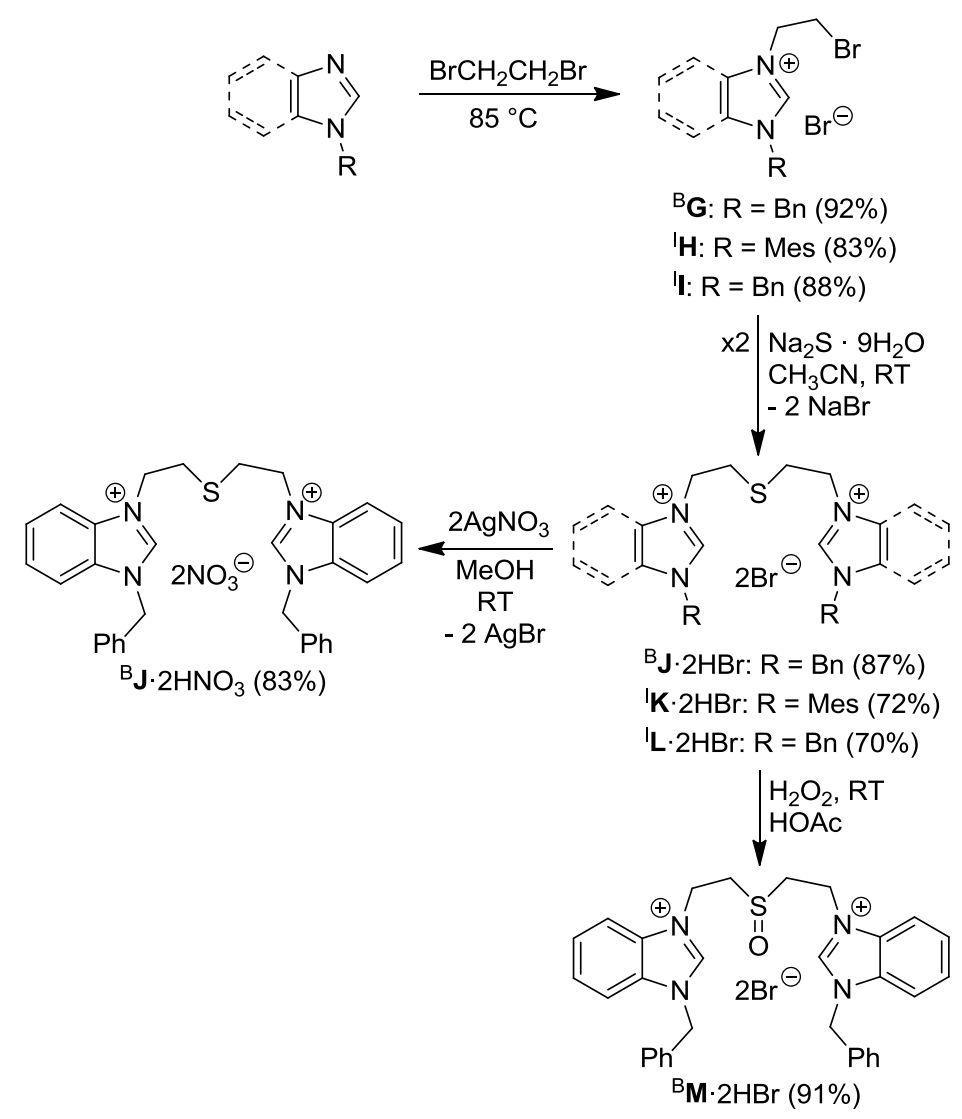


The reaction of benzylbenzimidazole with neat dibromoethane afforded 1-benzyl-3bromoethylbenzimidazolium bromide ${ }^{\mathrm{B}} \mathbf{G}$, which is a useful precursor to salts with different functional groups (vide infra). Two equiv of ${ }^{\mathrm{B}} \mathbf{G}$ underwent nucleophilic substitution with $\mathrm{Na}_{2} \mathrm{~S}$ to form the thioether-bridged dibenzimidazolium dibromide ${ }^{\mathrm{B}} \mathbf{J} \cdot 2 \mathrm{HBr}$. Anion exchange occurred smoothly by reacting ${ }^{\mathrm{B}} \mathbf{J} \cdot 2 \mathrm{HBr}$ with two equiv of $\mathrm{AgNO}_{3}$ affording ${ }^{\mathrm{B}} \mathbf{J} \cdot 2 \mathrm{HNO}_{3}$ with the precipitation of $\mathrm{AgBr}$. In addition, the sulfoxide-bridged dibenzimidazolium salt ${ }^{\mathrm{B}} \mathbf{M} \cdot 2 \mathrm{HBr}$ was prepared by oxidation of the thioether ${ }^{\mathrm{B}} \mathbf{J} \cdot 2 \mathrm{HBr}$ with three equiv of $\mathrm{H}_{2} \mathrm{O}_{2}$ in acetic acid at ambient temperature.

Similarly, the thioether-bridged diimidazolium salts ${ }^{\mathrm{I}} \mathbf{K} \cdot 2 \mathrm{HBr}$ and ${ }^{\mathrm{I}} \mathbf{L} \cdot 2 \mathrm{HBr}$ can be synthesized from N-substituted imidazoles in two steps (Scheme 2). The first step involved quaternation of 1-mesitylimidazole and 1-benzylimidazole with neat 1,2-dibromoethane affording salts ${ }^{\mathrm{I}} \mathbf{H}$ and ${ }^{\mathrm{I}} \mathbf{I}$, which were treated with $\mathrm{Na}_{2} \mathrm{~S}$ giving rise to thioether-bridged ligand precursors ${ }^{\mathrm{I}} \mathbf{K} \cdot 2 \mathrm{HBr}$ and ${ }^{\mathrm{I}} \mathbf{L} \cdot 2 \mathrm{HBr}$.

This successful strategy for the synthesis of ${ }^{\mathrm{I}} \mathbf{K} \cdot 2 \mathrm{HBr}$, however, failed in the preparation of the electron poorer 4,5-dichlorodiimidazolium-analogue ${ }^{\mathrm{Cl}} \mathbf{P} \cdot 2 \mathrm{HBr}$ (Scheme 3). Apparently, 1-benzyl-4,5dichloroimidazole is too electron deficient to be alkylated by 1,2-dibromoethane to afford the illusive species " $\mathbf{X}$ ".

To circumvent this problem, another synthetic route was developed (Scheme 3) [10], in which the thioether-bridge was installed first followed by quaternation with the stronger electrophile benzylbromide. Thus, 4,5-dichloroimidazole was first alkylated with 1,2-dibromoethane to yield 1bromoethyl-4,5-dichloroimidazole $\mathbf{N}$, which was then treated with $\mathrm{Na}_{2} \mathrm{~S}$ to form the sulfur-bridged diimidazole $\mathbf{O}$. Alkylation of $\mathbf{O}$ with benzylbromide finally afforded the target compound ${ }^{\mathrm{Cl}} \mathbf{P} \cdot 2 \mathrm{HBr}$.

Scheme 3. Synthesis of thioether-bridged 4,5-dichlorodiimidazolium salt ${ }^{\mathrm{Cl}} \mathbf{P} \cdot 2 \mathrm{HBr}$ [10].
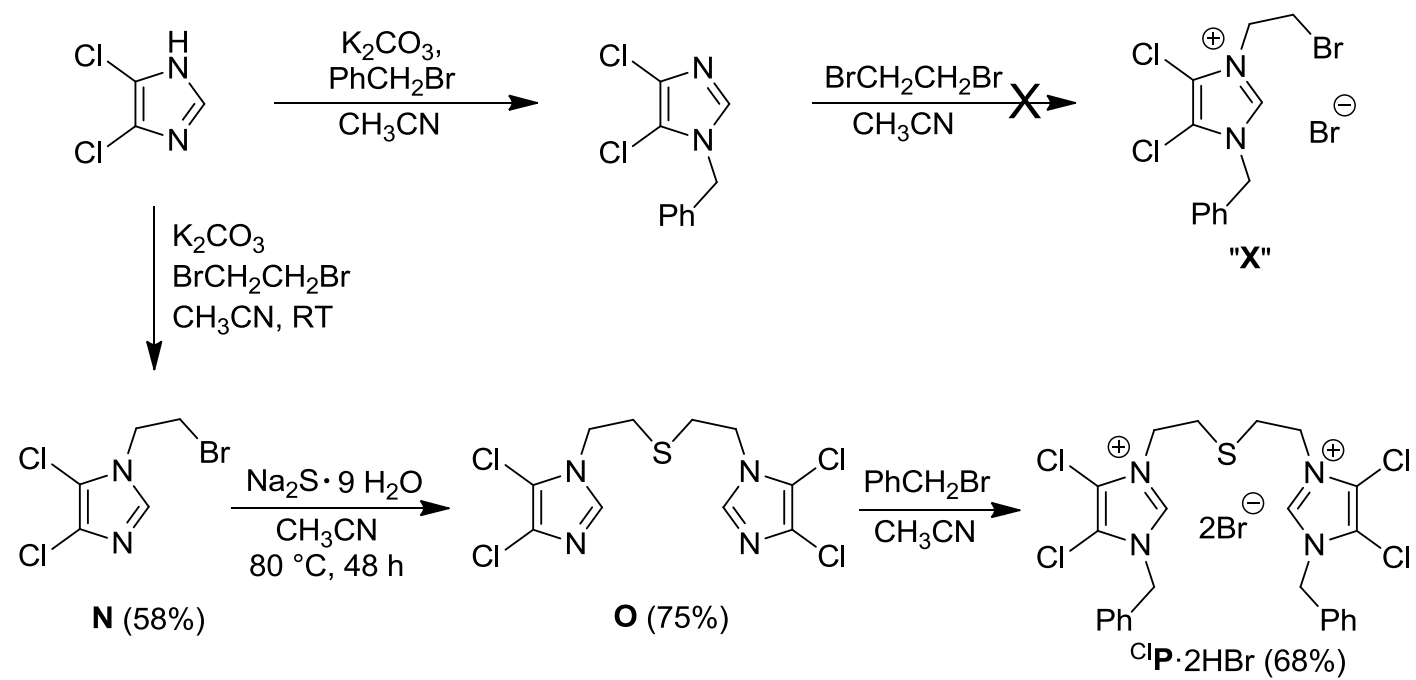

\subsection{Thioester- and Thiol-Functionalized Azolium Salts}

Nucleophilic substitution of salt ${ }^{\mathrm{B}} \mathbf{G}$ with 1.2 equiv of $\mathrm{KSCOCH}_{3}$ in $\mathrm{CH}_{3} \mathrm{CN}$ afforded the thioesterfunctionalized benzimidazolium salt ${ }^{\mathrm{B}} \mathbf{Q} \mathrm{Ac} \cdot \mathrm{HBr}$ (Scheme 4) [11]. In a similar manner, imidazolium analogue ${ }^{\mathrm{I}} \mathbf{R} \mathrm{Ac} \cdot \mathrm{HBr}$ was obtained as a brown oil from ${ }^{\mathrm{I}} \mathbf{H}[12]$. The thioester group of ${ }^{\mathrm{B}} \mathbf{Q A c} \cdot \mathrm{HBr}$ was easily hydrolyzed by aqueous $\mathrm{HBr}$ to form the thiol-functionalized salt ${ }^{\mathrm{B}} \mathbf{Q} \cdot \mathrm{H}_{2} \mathrm{Br}$. 
Scheme 4. Syntheses of thioester/thiol-functionalized azolium salts [11,12].

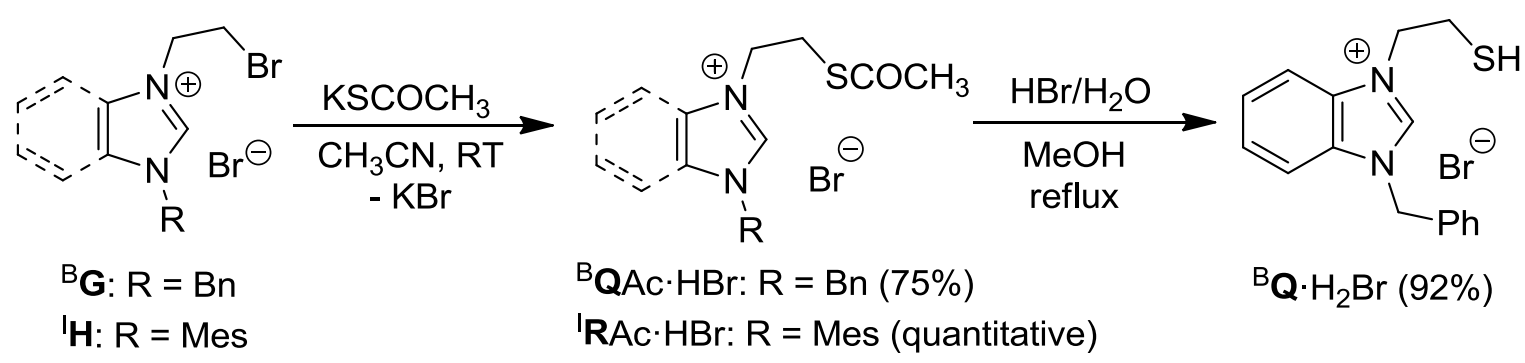

\subsection{Thiophene-Functionalized Azolium Salt}

The thiophene-functionalized benzimidazolium bromide ${ }^{\mathrm{B}} \mathbf{T} \cdot \mathrm{HBr}$ was synthesized from the commercially available 2-thiophenemethanol, which was brominated with $\mathrm{PBr}_{3}$ and heated with $N$-methylbenzimidazole to afford the desired compound (Scheme 5) [13].

Scheme 5. Synthesis of the thiophene-functionalized benzimidazolium salt ${ }^{\mathrm{B}} \mathbf{T} \cdot \mathrm{HBr}[13]$.
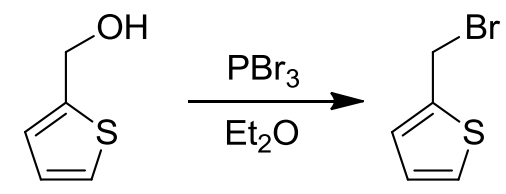

S $(89 \%)$
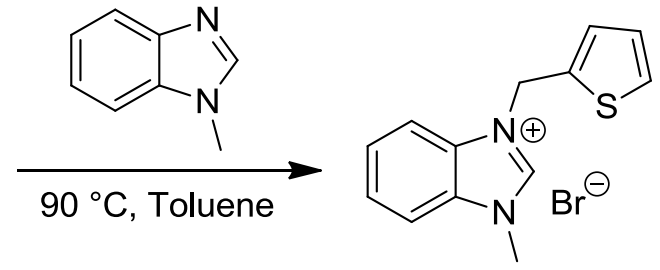

$\mathrm{B}_{\mathrm{T}} \cdot \mathrm{HBr}(78 \%)$

\section{Thioether-NHC Complexes}

The thioether group is the most common among the sulfur-functions described in this work [6,14]. Using thioether-functionalized NHCs and diNHCs a range of bis(carbene), monocarbene, CSC pincer and pseudopincer complexes of palladium have been obtained, which are described in the following paragraphs in more detail. Notably, the first experimental evidence for the true hemilabile coordination behavior of a donor-functionalized NHC was presented using a thioether-NHC Pd(II) complex.

\subsection{Thioether-Functionalized Pd(II) Bis(carbene) Complexes}

The complexation of two equiv of ${ }^{\mathrm{I}} \mathbf{E}_{\mathbf{a}} \cdot \mathrm{HBr}$ with $\mathrm{Pd}(\mathrm{OAc})_{2}$ in acetonitrile at $90{ }^{\circ} \mathrm{C}$ gave rise to a complex product mixture, from which only cis- $\left[\mathrm{PdBr}_{2}\left({ }^{\mathrm{I}} \mathbf{E}_{\mathbf{a}}\right)_{2}\right]$ (cis-1a) could be isolated in a low yield of $38 \%[7,8]$. The difficulty of carbene formation and subsequent coordination to the Pd(II) center can be attributed to competing processes such as (i) nonselective coordination of the soft sulfur atom, (ii) competing deprotonation of $\mathrm{C} 4 / \mathrm{C} 5$ - or benzylic protons. Thus the alternative and milder Ag-carbene transfer method was explored (Scheme 6) [15]. Two equiv of ${ }^{\mathrm{I}} \mathbf{E}_{\mathbf{a}} \cdot \mathrm{HBr}$ were treated with $\mathrm{Ag}_{2} \mathrm{O}$ in $\mathrm{CH}_{2} \mathrm{Cl}_{2}$, and the resulting $\mathrm{Ag}$-carbene species was added into an $\mathrm{CH}_{3} \mathrm{CN}$ solution of $\left[\mathrm{PdBr}_{2}\left(\mathrm{CH}_{3} \mathrm{CN}\right)_{2}\right]$. As expected, an isomeric mixture of bis(carbene) complexes cis-1a (45\%), trans-anti-1a (27\%), and trans-syn-1a (27\%) was obtained in an improved yield of $98 \%$. 
Similar reaction conditions were applied for the complexation of imidazolium salt ${ }^{\mathrm{I}} \mathbf{E}_{\mathbf{b}} \cdot \mathrm{HBr}$, and an approximately 1:1 mixture of trans-anti-[ $\left.\operatorname{PdBr}_{2}\left({ }^{\mathrm{I}} \mathbf{E}_{\mathbf{b}}\right)_{2}\right]$ (trans-anti-1b) and trans-syn-1b was isolated (Scheme 6). Surprisingly, cis-isomers were not detected.

Scheme 6. Syntheses of thioether-functionalized Pd(II) bis(imidazolin-2-ylidene) complexes [7,8].

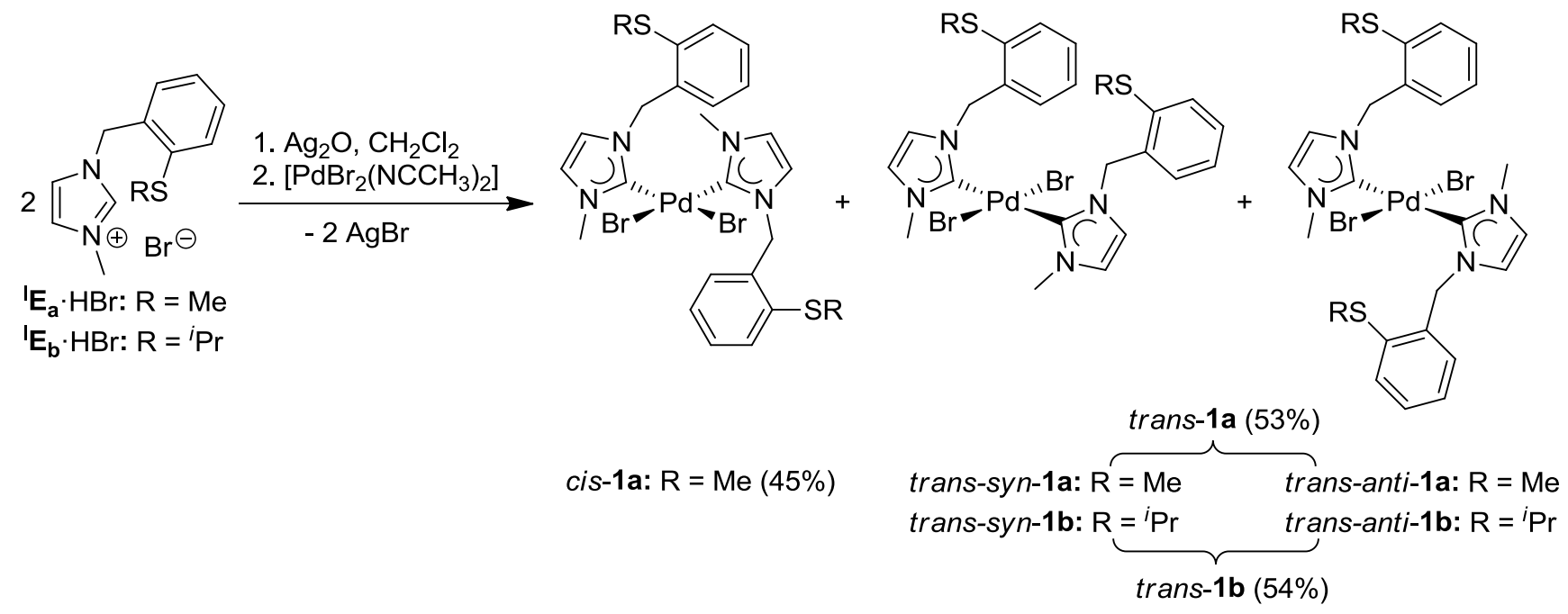

Due to the absence of additional acidic protons on the heterocyclic backbone, the benzimidazolium salts ${ }^{\mathrm{B}} \mathbf{F}_{\mathbf{a}} \cdot \mathrm{HBr}$ and ${ }^{\mathrm{B}} \mathbf{F}_{\mathbf{b}} \cdot \mathrm{HBr}$ reacted more cleanly with $\mathrm{Pd}(\mathrm{OAc})_{2}$ compared to their imidazolium analogues, giving rise to cis-configured complexes cis- $\left[\mathrm{PdBr}_{2}\left({ }^{\mathrm{B}} \mathbf{F}_{\mathbf{a} / \mathbf{b}}\right)_{2}\right]($ cis-2a/b) in yields of $89 \%$ and $67 \%$, respectively (Scheme 7) [8].

Scheme 7. Syntheses of thioether-functionalized Pd(II) bis(benzimidazolin-2-ylidene) complexes [8].

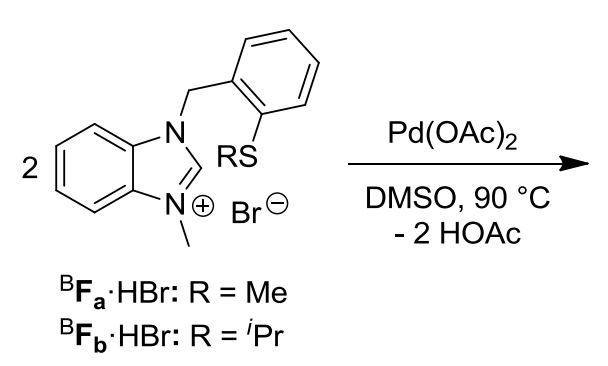

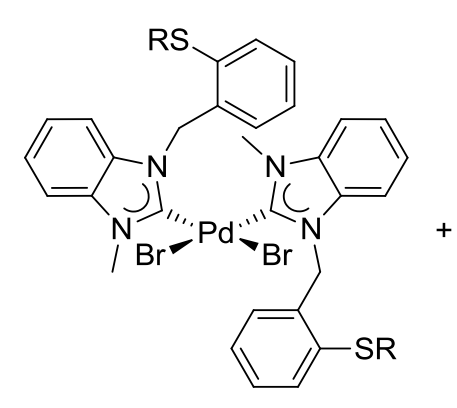

cis-2a: $\mathrm{R}=\mathrm{Me}(89 \%)$ cis-2b: $\mathrm{R}={ }^{i} \operatorname{Pr}(67 \%)$

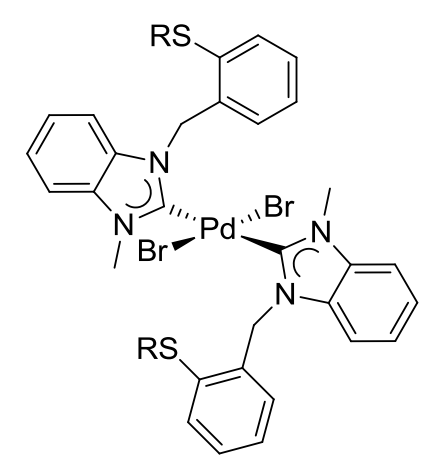

trans-anti-2b: $\mathrm{R}={ }^{i} \mathrm{Pr}$

The molecular structures of cis-1a, trans-anti-1b, and cis-2a have been obtained from X-ray diffraction analysis on single crystals (Figure 2). In addition, cis-trans isomerization of cis-2b occurred upon crystallization, which gave rise to the solid state structure of trans-anti-2b. All structures show that each Pd(II) center adopts a square-planar geometry, coordinated by two NHCs and two bromido ligands, while the thioether functions remain pendant. Overall, it was observed that cis-isomers preferably crystallized when $\mathrm{R}=\mathrm{CH}_{3}$, while crystals of trans-isomers form when $\mathrm{R}=\mathrm{CH}\left(\mathrm{CH}_{3}\right)_{2}$. It is interesting to note that changes remote from the metal center can trigger cis-trans isomerization in these bis(carbene) complexes. 
Figure 2. Molecular structures of cis-1a, trans-anti-1b, cis-2a and trans-anti-2b [8].

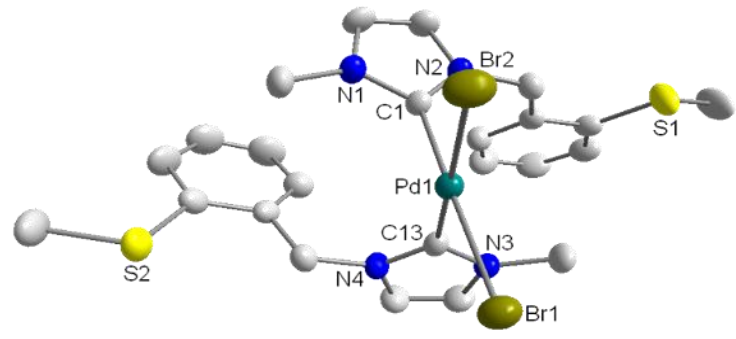

cis-1a

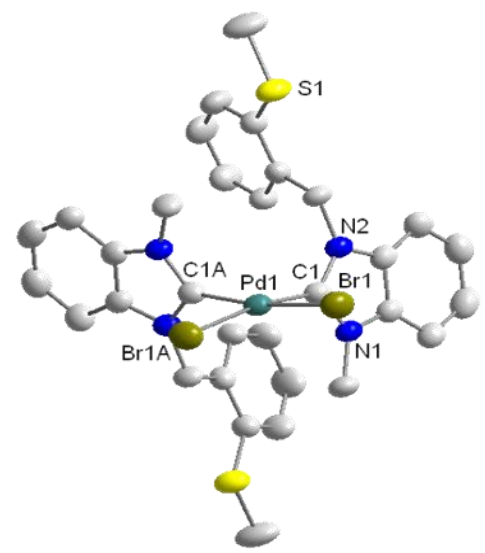

cis-2a

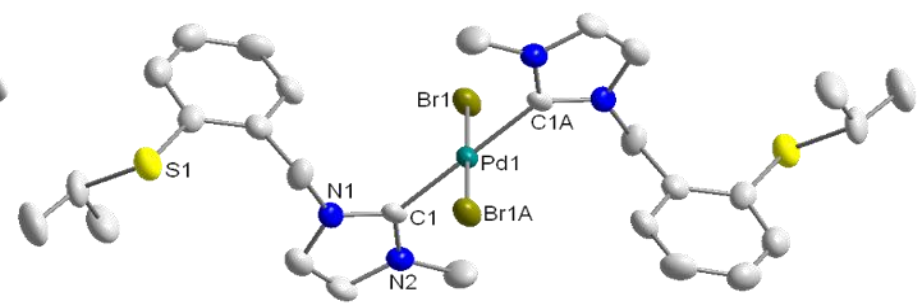

trans-anti-1b

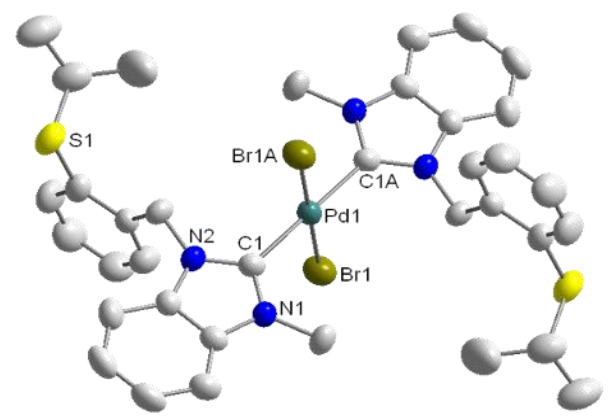

trans-anti-2b

\subsection{Hemilabile Thioether-Functionalized Pd(II) Monocarbene Complexes}

To synthesize monocarbene complexes, which should allow thioether coordination, the Ag-carbene transfer reaction with a 1:1 stoichiometric ratio of ${ }^{\mathrm{I}} \mathbf{E}_{\mathbf{a}} \cdot \mathrm{HBr}$ to $\mathrm{Pd}$ was employed (Figure 3) [7,8]. The ${ }^{1} \mathrm{H}-\mathrm{NMR}$ spectrum of the reaction product in $\mathrm{CDCl}_{3}$ shows very broad signals at ambient temperature (Figure 4). Upon cooling to $-30{ }^{\circ} \mathrm{C}$, two doublets at 5.00 and $5.85 \mathrm{ppm}$ were resolved for the nonequivalent benzylic protons, which indirectly indicate coordination of the sulfur function. The identity of complex cis-[ $\left.\operatorname{PdBr}_{2}\left({ }^{\mathrm{I}} \mathbf{E}_{\mathbf{a}}-\kappa^{2} C, S\right)\right]$ (3) was finally confirmed by X-ray diffraction, which shows that the carbene and the sulfur atom coordinate to the metal center in a cis-chelating manner, resulting in a seven-membered ring (Figure 3). The newly formed Pd-S bond amounts to 2.3079(3) A.

Figure 3. Synthesis of $\mathrm{Pd}(\mathrm{II})$ monocarbene complex 3 and its molecular structure $[7,8]$.

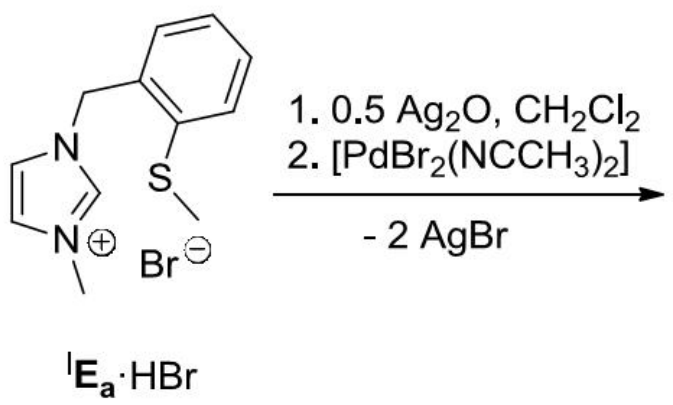

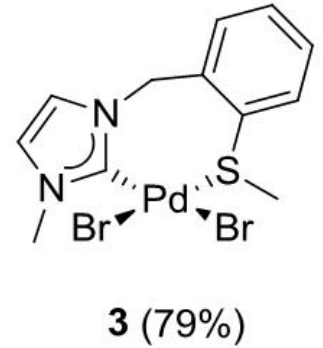

$3(79 \%)$

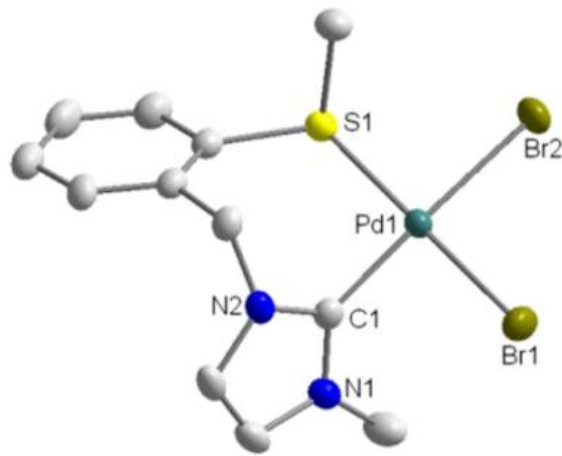


Figure 4. ${ }^{1} \mathrm{H}$-NMR spectrum of $\mathbf{3}\left(300 \mathrm{MHz}, \mathrm{CDCl}_{3}\right)$.

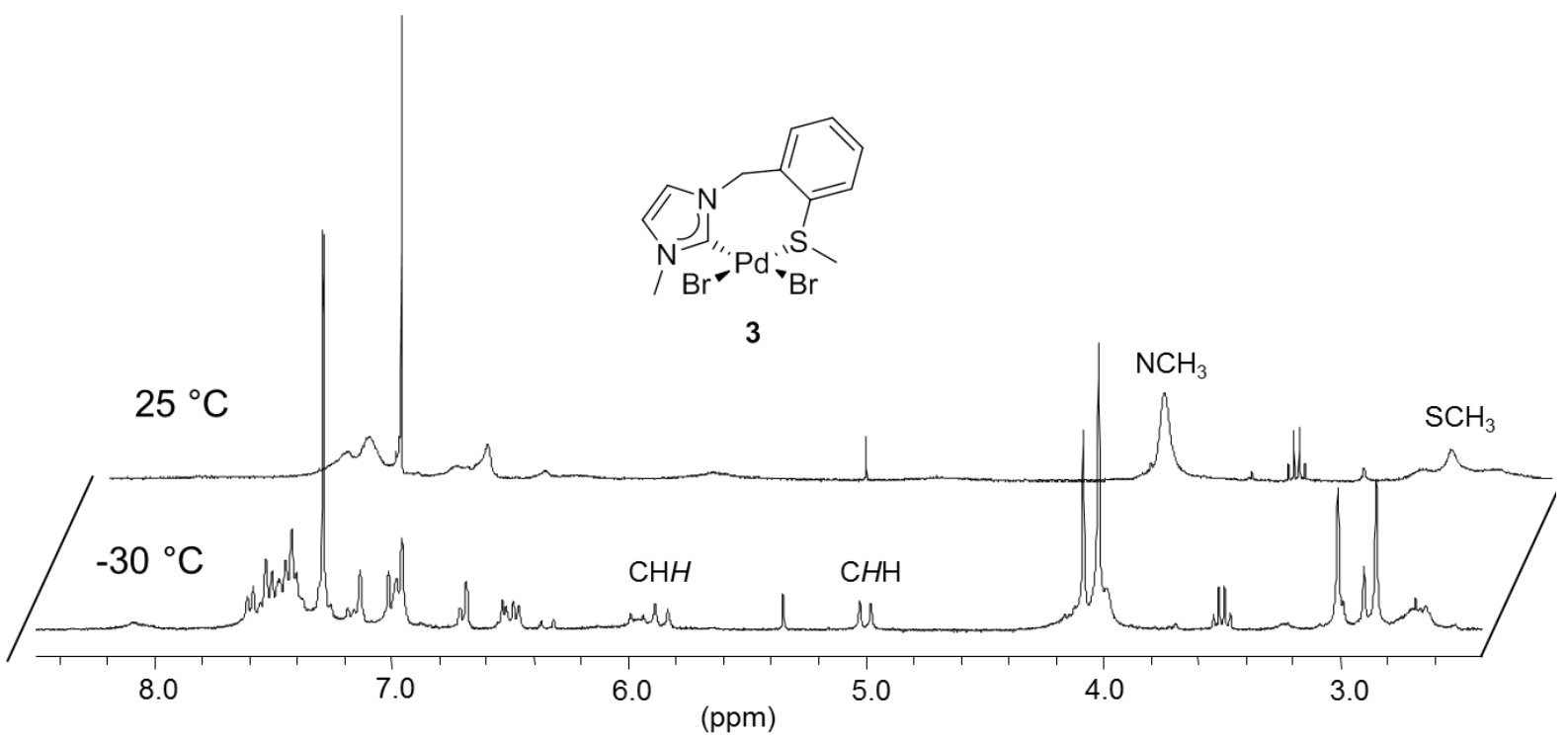

The complicated ${ }^{1} \mathrm{H}-\mathrm{NMR}$ spectrum of complex 3 was mainly attributed to two dynamic processes that occur in solution (Scheme 8). The first process involves flipping of the seven-membered ring, and syn- and anti-isomerization, which slows down upon cooling, giving rise to the inequivalent benzylic protons observed at low temperature.

Scheme 8. Dynamic process due to the hemilabile ligand in complex 3.

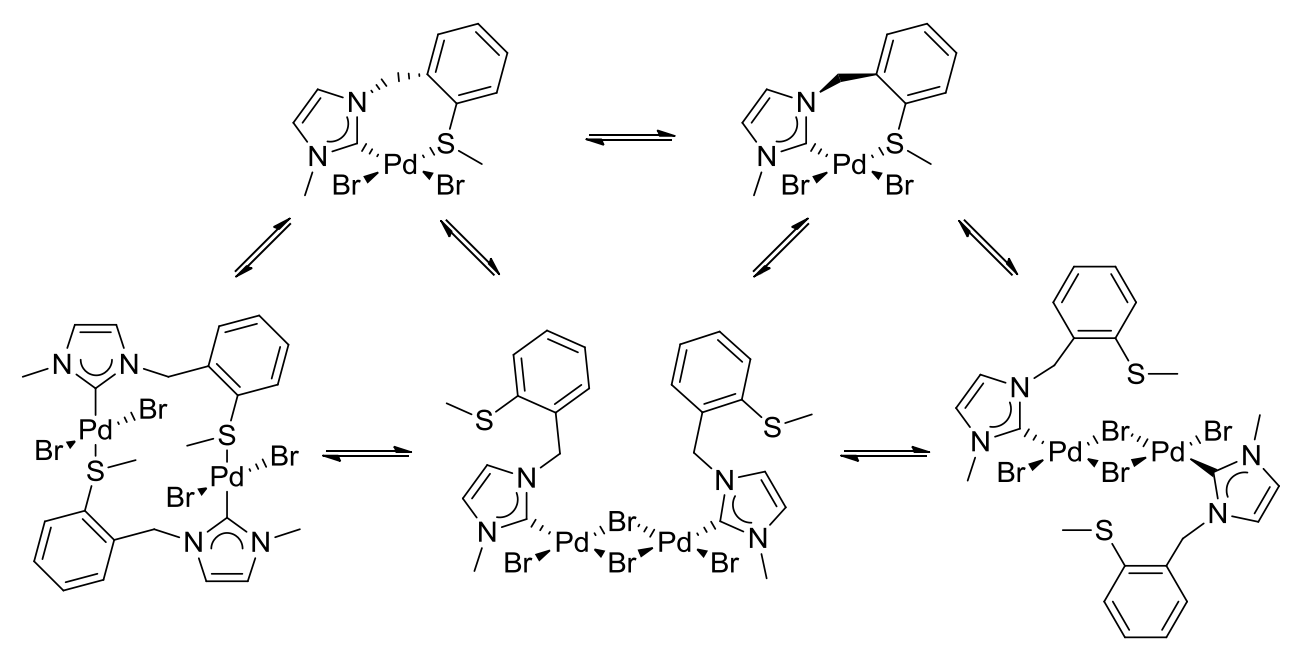

The second process involves reversible de- and recoordination of the sulfur donor in a hemilabile fashion. Decoordination results in a formally unsaturated metal center, which stabilizes itself upon dimerization. The two dynamic processes are in equilibrium with potentially at least five different species. The situation is further complicated due to the fact that the thioether function becomes a chiral center upon coordination.

The hemilabile behavior of the thioether-NHC ligand was finally confirmed by the addition of one equiv (based on $\mathrm{Pd}$ ) of $\mathrm{PPh}_{3}$ to the solution of 3 (Figure 5) [7,8]. The stronger phosphine donor is expected to cleave potential dimeric complexes as well as the weaker Pd-S bond in $\mathbf{3}$. Indeed, the addition of $\mathrm{PPh}_{3}$ led to the formation of the mixed NHC-phosphine complex cis-[PdBr $\left.2\left(\mathbf{E}_{\mathbf{a}}\right)\left(\mathrm{PPh}_{3}\right)\right](\mathbf{4})$ 
as the sole product, as evidenced by clean and well-resolved multi-nuclear NMR spectra (Figure 6) as well as X-ray diffraction analysis (Figure 5).

Figure 5. Synthesis of Pd(II) monocarbene complex $\mathbf{4}$ and its molecular structure $[7,8]$.<smiles>C[n+]1ccn2c1[Pb](Br)(Br)[13C](Br)c1ccccc1C2</smiles>

3

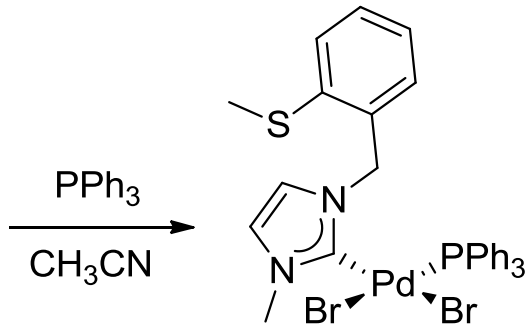

$4(64 \%)$

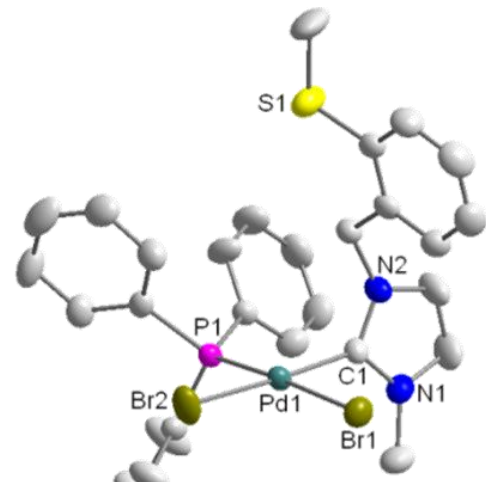

4

Figure 6. ${ }^{1} \mathrm{H}-\mathrm{NMR}$ spectrum of $4\left(300 \mathrm{MHz}, \mathrm{CDCl}_{3}\right)$.

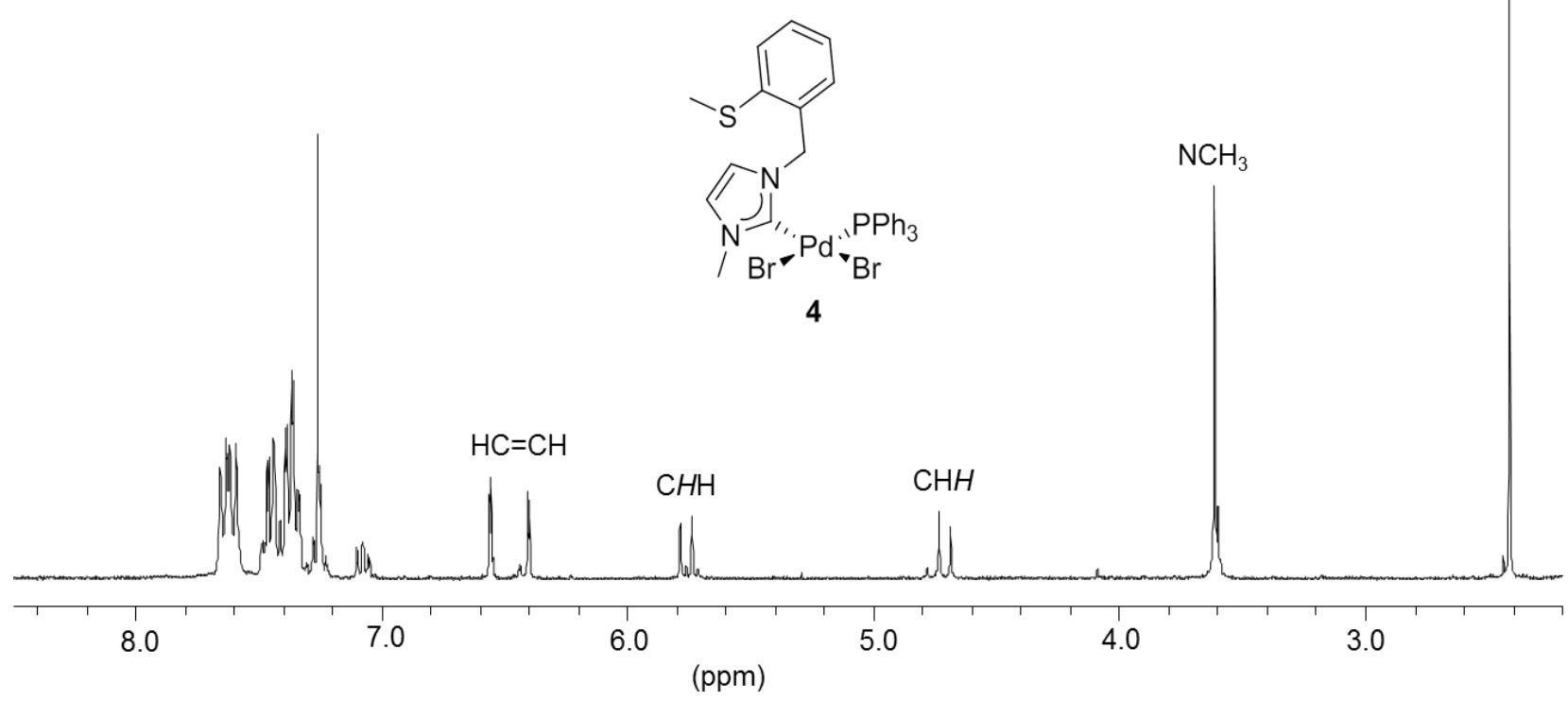

\section{CSC-Pincer Type Pd(II) Complexes}

Most known pincer systems contain rather rigid structures, which are intended to yield increased complex stability $[16,17]$. On the other hand, a more flexible ligand backbone would allow a more subtle interplay between lability and stability, which may be beneficial for certain types of catalytic applications. Thus, we investigated the syntheses of $\mathrm{Pd}(\mathrm{II})$ complexes with CSC-pincer type ligands using thioether-bridged diazolium salts. 


\subsection{Pd(II) Benzimidazolin-2-ylidene Complexes}

Palladation of the thioether-bridged benzimidazolium salt ${ }^{\mathrm{B}} \mathbf{J} \cdot 2 \mathrm{HBr}$ with $\mathrm{Pd}(\mathrm{OAc})_{2}$ led to the pseudo-pincer dicarbene complex cis- $\left[\mathrm{PdBr}_{2}\left({ }^{\mathrm{B}} \mathbf{J}-\kappa^{2} C\right)\right](\mathbf{5})$, in which the thioether function remains pendant (Scheme 9) [9]. Similarly, the reaction of precursor ${ }^{\mathrm{B}} \mathbf{M} \cdot 2 \mathrm{HBr}$ gave an analogous complex cis- $\left[\mathrm{PdBr}_{2}\left({ }^{\mathrm{B}} \mathbf{M}-\kappa^{2} C\right)\right]$ (6), which is to date the only example of a complex bearing a sulfoxide-functionalized NHC ligand. The pseudo-pincer configurations of both complexes have been confirmed by their solid state structures (Figure 7).

Scheme 9. Syntheses of Pd(II) complexes with benzimidazolin-2-ylidene CSC-pincer type ligands [9].

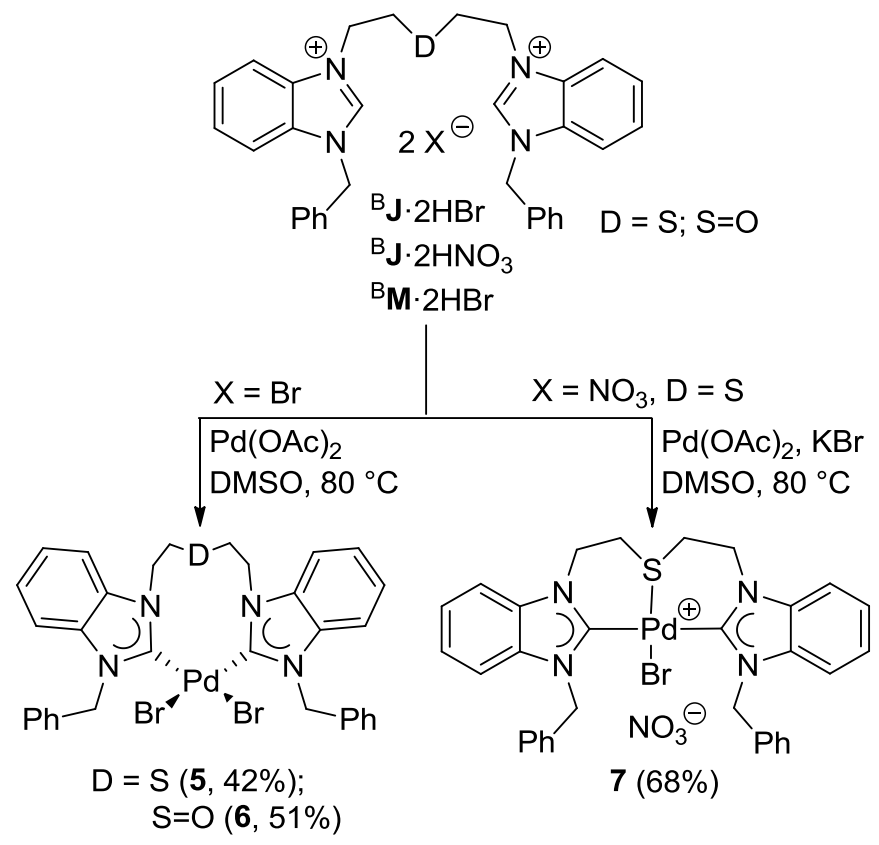

Figure 7. Molecular structures of 5 and 6 [9].

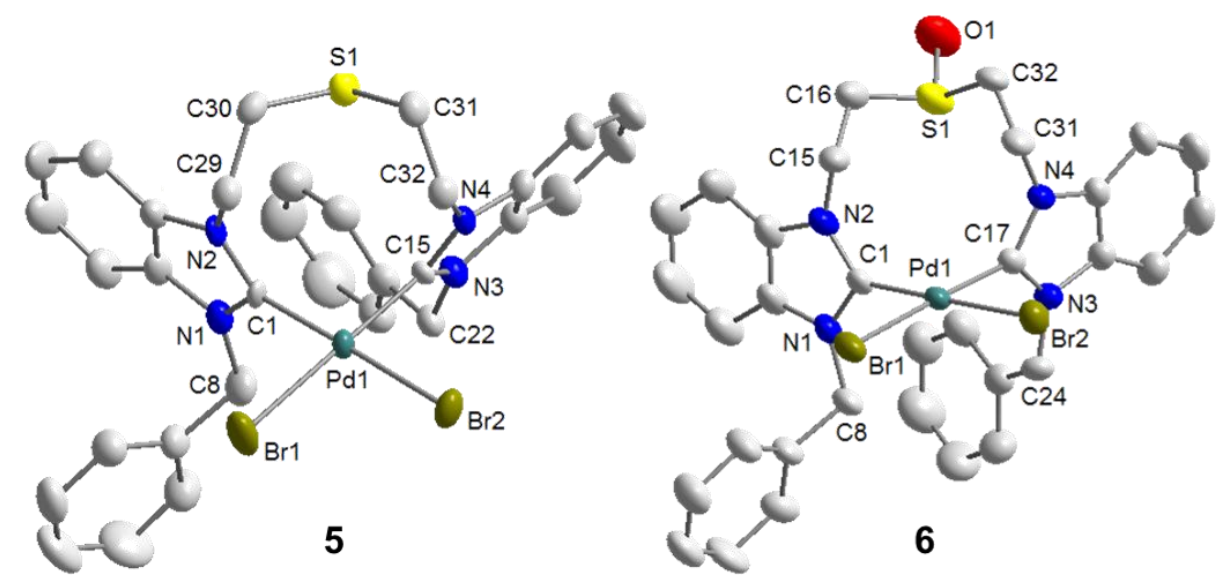

In an attempt to overcome the formation of pseudo-pincer complexes and to enforce a CSC-pincertype coordination mode of ligand ${ }^{\mathrm{B}} \mathbf{J}$, ligand precursor ${ }^{\mathrm{B}} \mathbf{J} \cdot 2 \mathrm{HBr}$ was substituted with ${ }^{\mathrm{B}} \mathbf{J} \cdot 2 \mathrm{HNO}_{3}$. The latter only contains weakly coordinating counter-anions, which should facilitate binding of the soft thioether donor. Disappointingly, the equimolar reaction of ${ }^{\mathrm{B}} \mathbf{J} \cdot 2 \mathrm{HNO}_{3}$ with $\mathrm{Pd}(\mathrm{OAc})_{2}$ in $\mathrm{DMSO}$ at $80{ }^{\circ} \mathrm{C}$ only led to substantial formation of Pd black. 
It was anticipated that the lack of stabilizing anionic ligands was the cause for this decomposition. Indeed with the addition of 1 equiv of $\mathrm{KBr}$, which provides a bromido ligand to take up the fourth coordination site, the reaction proceeded smoothly and the desired product trans- $\left[\operatorname{PdBr}\left({ }^{\mathrm{B}} \mathbf{J}-\kappa^{3} C S C\right)\right] \mathrm{NO}_{3}$ (7) could be isolated in a good yield of 68\% (Scheme 9). The solid state structure of 7 shows that the pincer-type coordination forces the two NHCs trans to each other, and the bromido ligand indeed binds to the Pd(II) center trans to the thioether donor (Figure 8). The Pd-S bond of 2.3078(18) $\AA$ is comparable to that of monocarbene complex $\mathbf{3}$ (vide supra).

Figure 8. Molecular structure of 7. The non-coordinating counter-anion $\mathrm{NO}_{3}{ }^{-}$has been omitted [9].

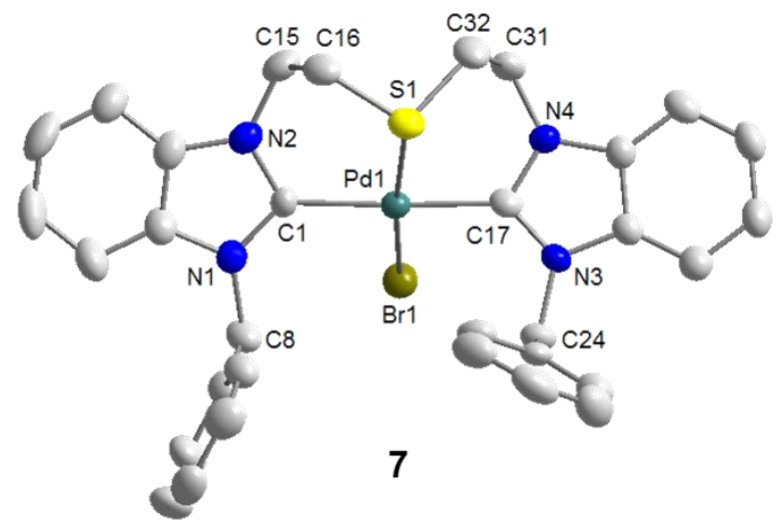

\subsection{Pd(II) Imidazolin-2-ylidene Complexes}

Although imidazolin-2-ylidenes are the most studied types of NHCs, their Pd(II) CSC-pincer complexes were unknown. Since the methodologies of synthesizing benzimidazole-based ligand precursors and complexes are straightforward (vide supra), an extension to imidazolin-2-ylidene systems was carried out [10].

Palladation of thioether-bridged imidazolium salt ${ }^{\mathrm{I}} \mathbf{K} \cdot 2 \mathrm{HBr}$ with $\mathrm{Pd}(\mathrm{OAc})_{2}$ afforded the cationic pincer complex trans-[PdBr$\left.\left({ }^{\mathrm{I}} \mathbf{K}-\kappa^{3} C S C\right)\right] \mathrm{Br}(\mathbf{8})$ with a bromide counter-anion (Scheme 10). Its formation can be attributed to the bulky mesityl substituents that enforce a trans configuration of the carbene donors, which in turn facilitates the coordination of the sulfur atom to the $\operatorname{Pd}(\mathrm{II})$ center enhancing the chelate effect of the CSC pincer ligand.

Scheme 10. Syntheses of CSC pincer complexes 8, 9 and pseudo-pincer complex 10.

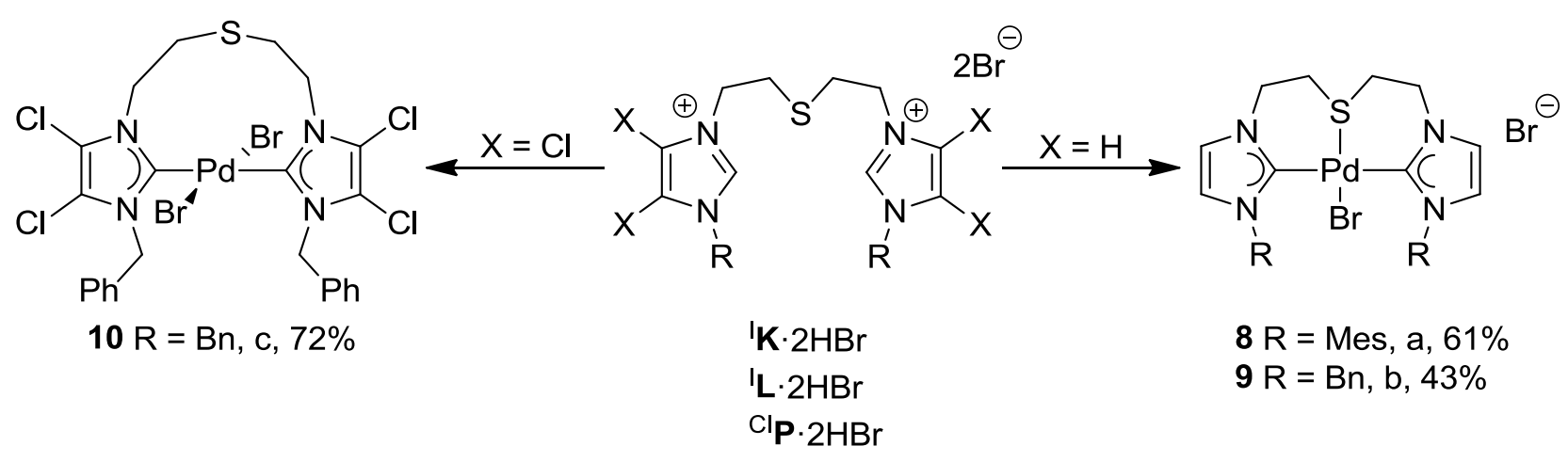

Reaction conditions: a: $\mathrm{Pd}(\mathrm{OAc})_{2}$, DMSO, $80{ }^{\circ} \mathrm{C}$; b: i) $\mathrm{Ag}_{2} \mathrm{O}, \mathrm{MeOH}$; ii) $\mathrm{PdBr}_{2}\left(\mathrm{CH}_{3} \mathrm{CN}\right)_{2}, \mathrm{CH}_{3} \mathrm{CN}$; c: i) $\mathrm{PdBr}_{2}, \mathrm{CH}_{3} \mathrm{CN}$; ii) $\mathrm{Ag}_{2} \mathrm{O}, \mathrm{CH}_{3} \mathrm{CN}[10]$. 
In order to study the steric influence in more detail, diimidazolium salt ${ }^{\mathrm{I}} \mathbf{L} \cdot 2 \mathrm{HBr}$ carrying less bulky and more flexible benzyl groups was subjected to complexation. Using the Ag-carbene transfer route, ${ }^{\mathrm{I}} \mathbf{L} \cdot 2 \mathrm{HBr}$ was converted to the pincer complex trans- $\left[\operatorname{PdBr}\left({ }^{\mathrm{I}} \mathbf{L}-\kappa^{3} C S C\right)\right] \mathrm{Br}(\mathbf{9})$ (Scheme 10), and its solid state molecular structure determined by X-ray diffraction analysis on single crystals is shown in Figure 9.

Figure 9. Molecular structures of $\mathbf{8 , 9}$ and $\mathbf{1 0}$ [10].
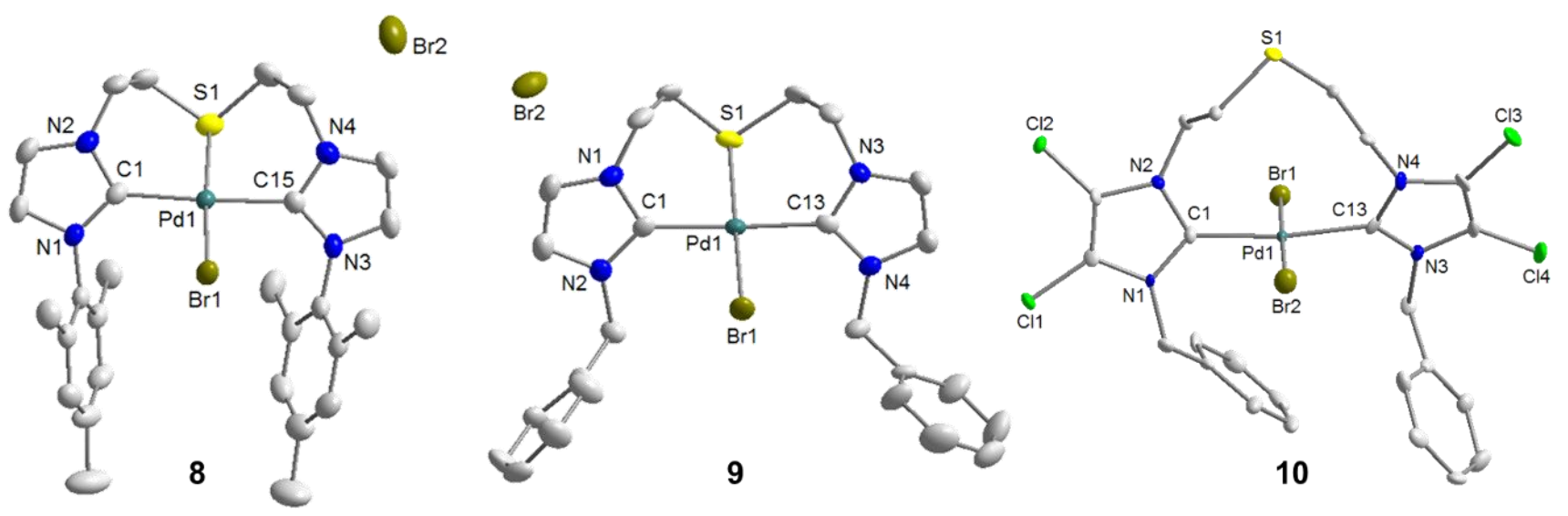

The straightforward formation of CSC pincer 9 from diimidazolium dibromide ${ }^{\mathrm{I}} \mathbf{L} \cdot 2 \mathrm{HBr}$ requires further comment, since palladation of the direct dibenzimidazolium analogue resulted in a neutral cis-dibromido-dicarbene complex 5 with dangling thioether function (vide supra). Since imidazolin-2ylidenes are generally stronger donors than benzimidazole analogues [18], it appears that the donor strength of carbenes influences pincer versus pseudo-pincer formation. Stronger donating carbenes may favor pincer formation even in the presence of halide ions, whereas weaker carbenes prefer to form neutral pseudo-pincer complexes (vide infra). In the latter case, pincer formation can be enforced by using salt precursors with non- or only weakly coordinating anions.

To find further proof for this concept, the synthesis of a $\mathrm{Pd}(\mathrm{II})$ complex bearing weakly donating 4,5-dichloroimidazolin-2-ylidenes derived from ${ }^{\mathrm{Cl}} \mathbf{P} \cdot 2 \mathrm{HBr}$ was carried out (Scheme 10). The ligand precursor ${ }^{\mathrm{C}} \mathbf{P} \cdot 2 \mathrm{HBr}$ was first treated with $\mathrm{PdBr}_{2}$ to yield a palladate, which was converted to a carbene complex with the addition of $\mathrm{Ag}_{2} \mathrm{O}$. Based on our hypothesis, a pseudo-pincer complex was anticipated. Indeed the pseudo-pincer complex trans-[PdBr$\left.\left({ }^{\mathrm{Cl}} \mathbf{P}-\kappa^{2} C\right)\right](\mathbf{1 0})$ was isolated, which was fully characterized by multinuclei NMR spectroscopies and X-ray analysis. The solid state structure depicts a trans-spanning dicarbene ligand with a pendant thioether function (Figure 9).

In the present case, we propose that the polarization between carbenes and the Pd(II) center is enhanced with stronger carbene donors (e.g., in 8 and 9), which leads to a pile-up of electron density at the bromido ligands making them a better leaving group, and eventually rendering the $\mathrm{Pd}(\mathrm{II})$ center more Lewis acidic for the coordination of the thioether donor. With weaker NHC donors (e.g., in 5, 6 and 10) such strong polarization is less likely, which results in a neutral pseudo-pincer complexes. In other words, stronger donors stabilize cationic pincer complexes more efficiently than weaker donors.

\section{Thiophene-NHC Complexes}

Reaction of two equiv of thiophene-functionalized salt ${ }^{\mathrm{B}} \mathbf{T} \cdot \mathrm{HBr}$ with $\mathrm{Pd}(\mathrm{OAc})_{2}$ afforded the desired bis(carbene) complex cis-17 (Figure 10) [13]. In its ${ }^{1} \mathrm{H}-\mathrm{NMR}$ spectrum, two sets of closely spaced 
signals are observed indicating the existence of an isomeric mixture. Moreover, the $\mathrm{NCH}_{2}$ protons become diastereotopic in the carbene complex cis-17 giving rise to a doublet for each proton (AA' spin system) (Figure 11), whereas their resonances are detected as singlets in the precursor ${ }^{\mathrm{B}} \mathbf{T} \cdot \mathrm{HBr}$. This observation is in agreement with a cis-arrangement of the two carbene ligands, in which a free rotation around the $\mathrm{Pd}-\mathrm{C}$ bond is restricted due to the steric repulsion of the bulky $\mathrm{N}$-thienylmethyl substituents. As a consequence, the two isomers have been assigned to cis-syn and cis-anti rotamers, in which the unsymmetrical carbene ligands differ in the orientation of their N-substituent. Notably, the presence of both rotamers is rarely observed in cis-configured complexes. Due to sterical reasons, the major set of signals is assigned to the cis-anti isomer. Correspondingly, two sets of signals are also observed in the ${ }^{13} \mathrm{C}$ NMR spectrum with two carbene resonances at 174.5 and $174.2 \mathrm{ppm}$, which are in the typical range observed for cis-bis(benzimidazolin-2-ylidene) complexes of $\mathrm{Pd}(\mathrm{II})$ [8]. The molecular structure of cis-17 obtained from X-ray diffraction analysis on single crystals revealed the sterically more favored cis-anti geometry.

Figure 10. Synthesis of thiophene-functionalized $\mathrm{Pd}(\mathrm{II})$ complex cis-17 and its molecular structure [13].
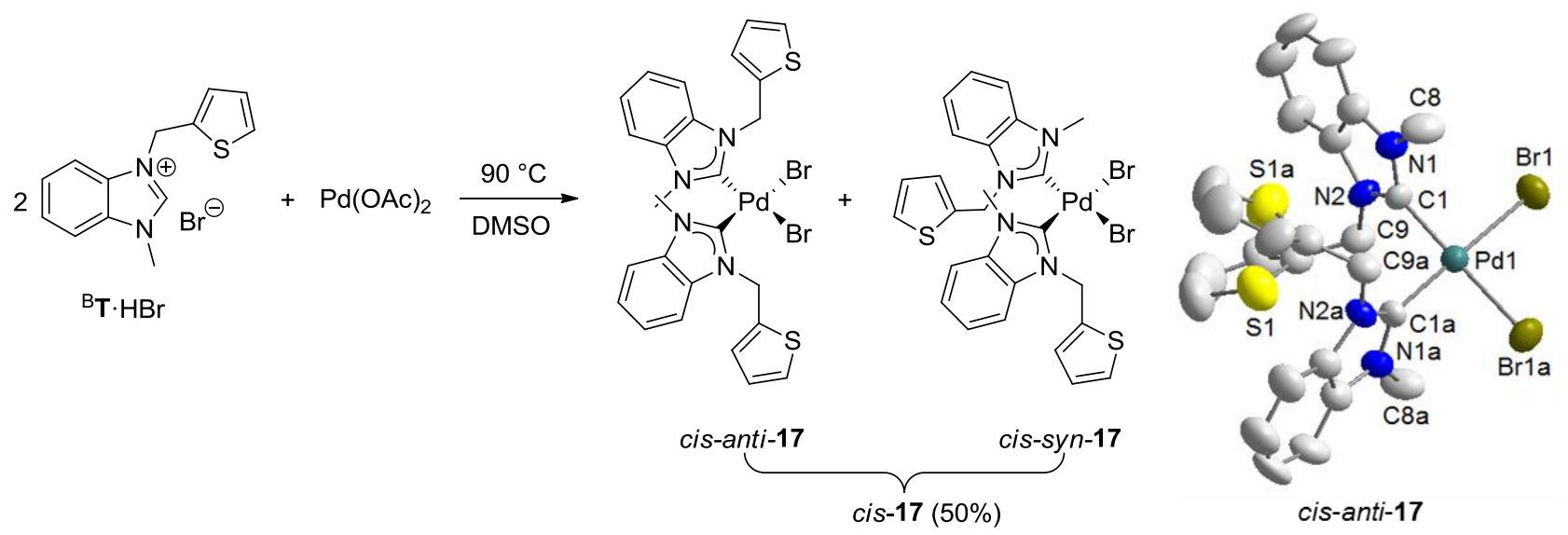

Figure 11. Diastereotopic ${ }^{1} \mathrm{H}-\mathrm{NMR}$ signals of $\mathrm{NCH}_{2}$ protons in cis-anti and cis-syn rotamers of cis-17 (500 MHz, $\left.\mathrm{CD}_{2} \mathrm{Cl}_{2}\right)$ [13].

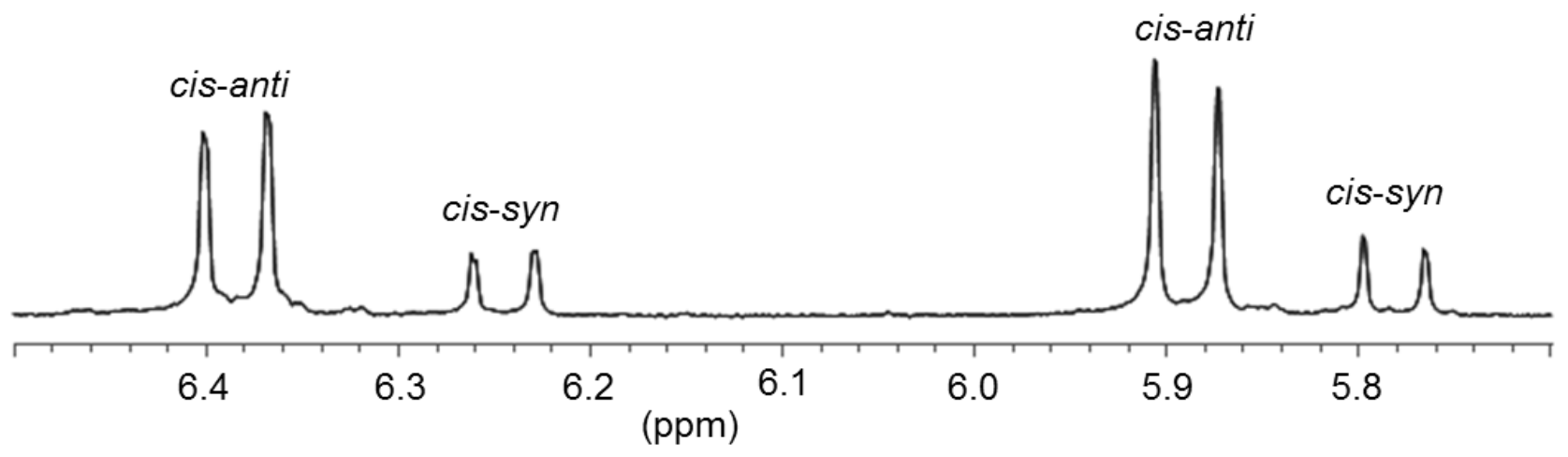

\section{Thiolato-NHC Complexes}

In comparison to the thioether group, the thiolato function is more electron rich and forms stronger metal sulfur bonds, which results in a versatile and diverse coordination chemistry. Although some 
methods of synthesizing thiolato-NHC complexes exist, they suffer from the limitation that air sensitive precursors, such as free thiols and metal(0) compounds, are required [19-21]. Furthermore, all reported examples are based on a saturated five- or six-membered N-heterocyclic ring system, while those based on benzimidazole and imidazole remain to be explored. Thus we explored simpler and more straightforward synthetic routes to thiolato-NHC complexes $[11,12]$.

\subsection{Thiolato-Bridged Pd(II) Complexes}

The reaction of thiol-functionalized salt ${ }^{\mathrm{B}} \mathbf{Q} \cdot \mathrm{H}_{2} \mathrm{Br}$ with one equiv of $\mathrm{Pd}(\mathrm{OAc})_{2}$ in degassed $\mathrm{CH}_{3} \mathrm{CN}$ under reflux yielded the thiolato-bridged dimeric $\mathrm{Pd}(\mathrm{II})$ benzimidazolin-2-ylidene complex $\left[\operatorname{PdBr}\left({ }^{\mathrm{B}} \mathbf{Q}\right.\right.$ $\left.\left.\kappa^{2} C, \mu-S\right)\right]_{2}(\mathbf{1 1})$ in a good yield of $76 \%$ (Scheme 11, method 1). More straightforwardly, it was found that the direct reaction of thioester salt ${ }^{\mathrm{B}} \mathrm{QAc} \cdot \mathrm{HBr}$ with one equiv of $\mathrm{Pd}(\mathrm{OAc})_{2}$ in $\mathrm{DMSO}$ at $80{ }^{\circ} \mathrm{C}$ also yielded complex 11 in a similar yield of 74\% (Scheme 11, method 2). Apparently, the methylthioester-function undergoes in situ hydrolysis probably assisted by free HOAc liberated from the deprotonation of ${ }^{\mathrm{B}} \mathbf{Q} \mathrm{Ac} \cdot \mathrm{HBr}$ with $\mathrm{Pd}(\mathrm{OAc})_{2}$. Alternatively, the hydrolysis may be activated by the coordination of the thioester to the Lewis acidic $\mathrm{Pd}(\mathrm{II})$ center. The resulting thiolate coordinates to the $\mathrm{Pd}(\mathrm{II})$ center, and subsequent dimerization affords the desired thiolato-bridged $\mathrm{Pd}(\mathrm{II})$ carbene complex 11, as evidenced by NMR spectroscopy and its solid state structure determined by X-ray diffraction (Figure 12). In this reaction, the thioester-function acts as a thiol-protecting group simplifying the synthesis of thiolato-complexes to a great extent. Method 2 is preferred over Method 1, since it shortens the reaction sequence and also eliminates the requirement to work under an inert atmosphere.

Scheme 11. Synthesis of thiolato-bridged Pd(II) benzimidazolin-2-ylidene complex 11 [11].
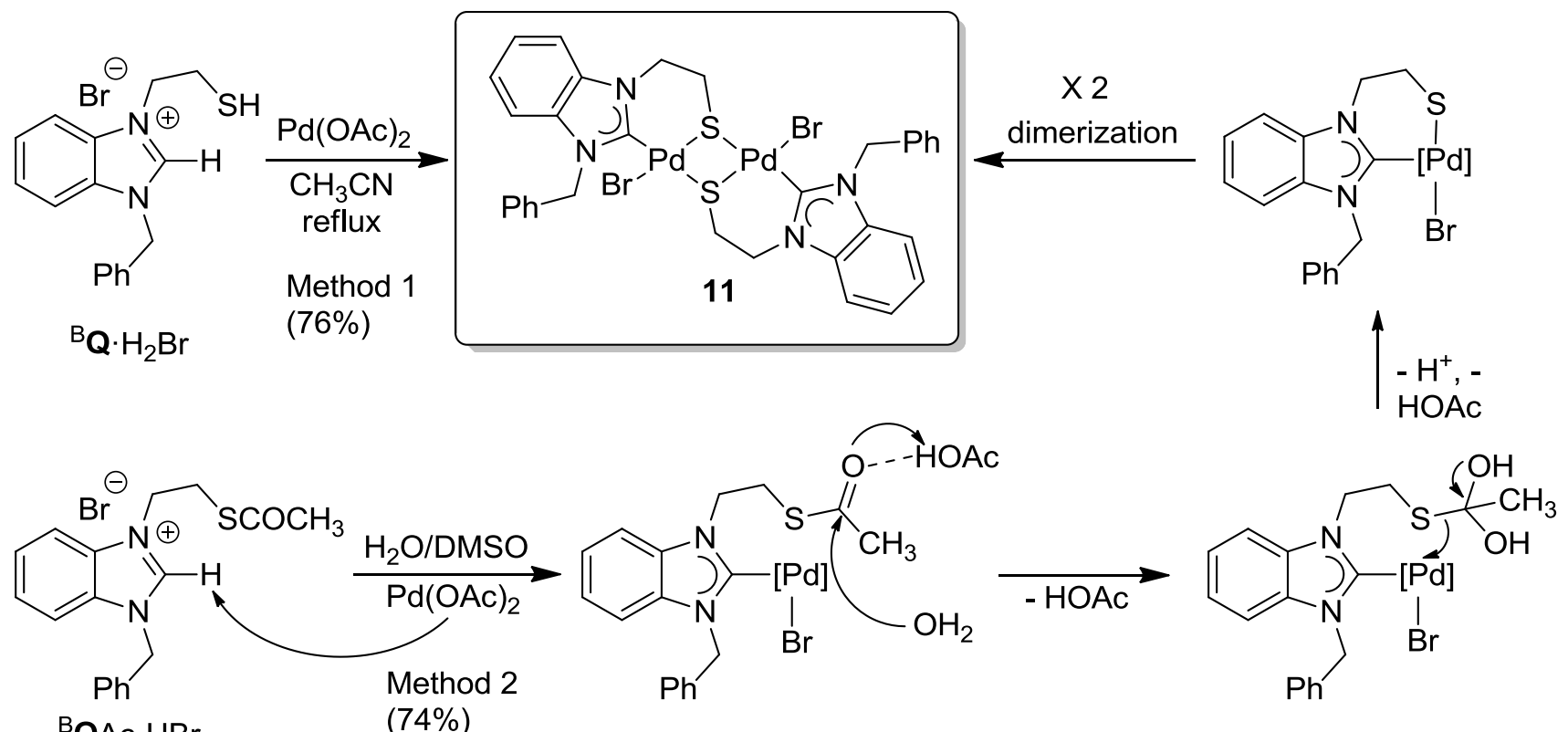

${ }^{B} \mathrm{QAC} \cdot \mathrm{HBr}$

$(74 \%)$ 
Figure 12. Molecular structure of 11 [11].

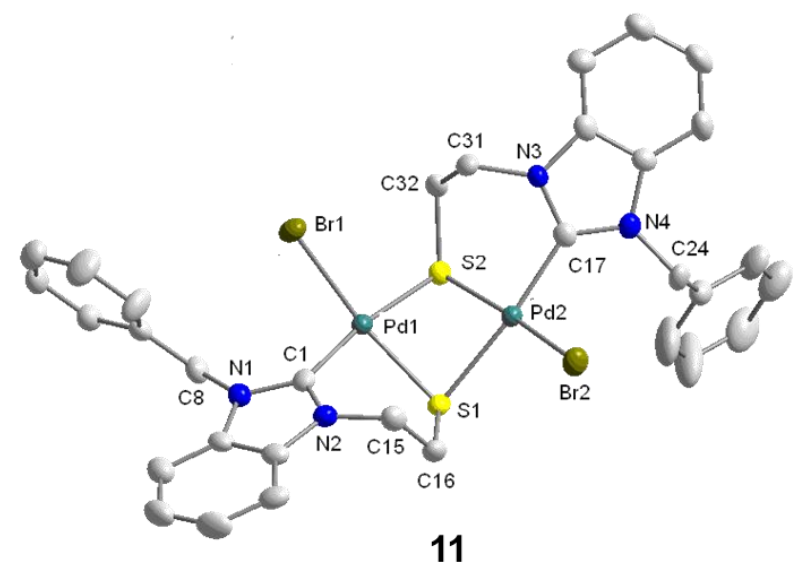

Similarly, the imidazolium thioester salt ${ }^{\mathrm{I}} \mathbf{R A c} \cdot \mathrm{HBr}$ was treated with one equiv of $\mathrm{Pd}(\mathrm{OAc})_{2}$ in DMSO at $80{ }^{\circ} \mathrm{C}$, which afforded a mixture of thiolato-bridged dinuclear $\left[\mathrm{Pd}_{2} \mathrm{~S}_{2}\right]$ carbene complexes in an overall yield $>72 \%$ (Scheme 12) [12]. Both the expected dimeric complex $\left[\operatorname{PdBr}\left({ }^{\mathrm{I}} \mathbf{R}-\kappa^{2} C, \mu-S\right)\right]_{2}(\mathbf{1 2})$ and its interesting constitutional isomer $\left[\operatorname{Pd}_{2} \mathrm{Br}_{2}\left({ }^{\mathrm{I}} \mathbf{R}-\kappa^{2} C, \mu-S\right)\left({ }^{\mathrm{I}} \mathbf{R}^{\prime}-\kappa^{2} C, \mu-S\right)\right]$ (13) were isolated. Compared to 12, the two NHCs in 13 adopt different coordination modes: one is bound to the Pd center via $\mathrm{C}(2)$ (normal bonding mode), while the other one coordinates via $\mathrm{C}(4)$ (mesoionic [22] bonding mode). The formation of the mesoionic carbene by competing deprotonation at $\mathrm{C}(4)$ probably helps to reduce the steric congestion caused by the bulky mesityl substituent.

Scheme 12. Syntheses of thiolato-bridged Pd(II) imidazolin-2-ylidene complexes [12].<smiles>CC(=O)CC[n+]1ccn(S(C)(=O)=O)c1</smiles>

'RAc.HBr

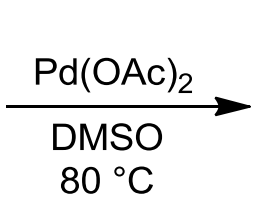

$80^{\circ} \mathrm{C}$

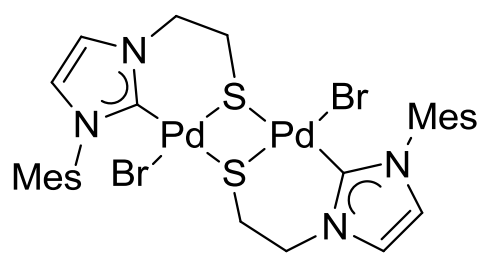

$12(44 \%)$

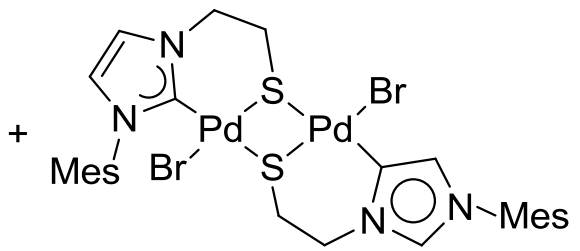

$13(28 \%)$

The formation of $\mathbf{1 3}$ is evidenced by NMR spectroscopy, which reveals distinct differences to complex 12 (Figure 13). Due to the unsymmetrical nature of compound $\mathbf{1 3}$ as a result of two different carbene ligands, its ${ }^{1} \mathrm{H}$ - and ${ }^{13} \mathrm{C}$-NMR spectra are more complicated and exhibit twice the number of signals compared to those of its isomer 12. More importantly, a sharp signal for the NCHN proton of the mesoionic carbene is still observed downfield at $8.90 \mathrm{ppm}$ in the ${ }^{1} \mathrm{H}-\mathrm{NMR}$ spectrum. Furthermore, the formations of both $\mathbf{1 2}$ and $\mathbf{1 3}$ were evidenced by their solid state structures (Figure 14) determined by single crystal X-ray diffraction.

To the best of our knowledge, complex $\mathbf{1 3}$ is the first example of a dinuclear complex, in which a normal NHC and its mesoionic isomer are coordinating two different metal centers within the same complex. In principle, this allows for a direct comparison of the two isomeric binding modes and their impact on bond parameters around each metal center. For example, the Pd-S bond [2.378(3) $\AA$ ] trans to the $\mathrm{C}(4)$ bound carbene is found to be longer than the one trans to the $\mathrm{C}(2)$ carbene [2.351(3) $\mathrm{A}$ ], implying a stronger trans influence of the former. 
Figure 13. Comparison of aromatic signals of ${ }^{1} \mathrm{H}-\mathrm{NMR}$ spectra of $12\left(500 \mathrm{MHz}, \mathrm{CDCl}_{3}\right)$ and 13 (500 MHz, DMSO-d6). The peaks marked with * correspond to solvents and the one with \# is due to the impurity.
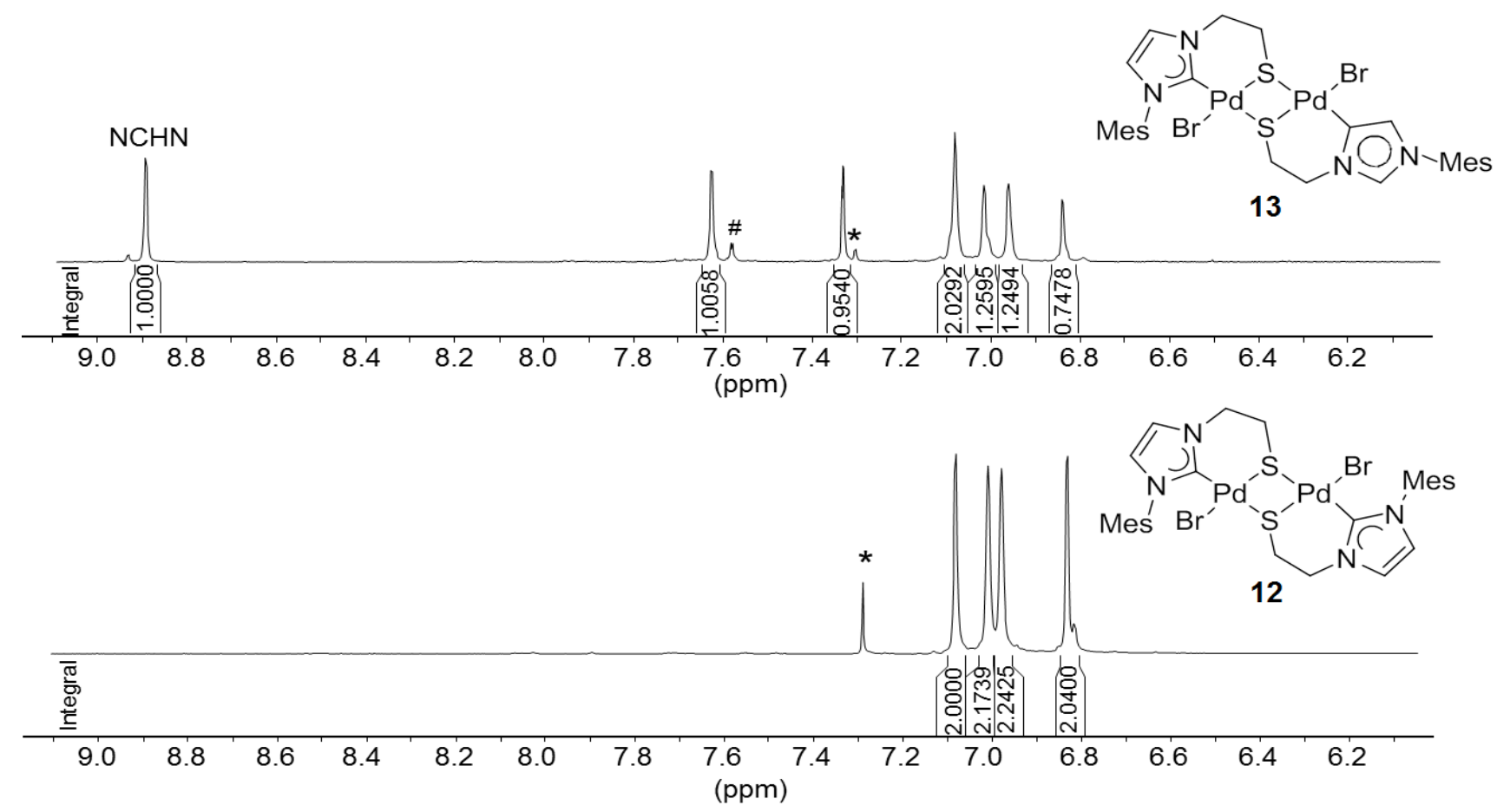

Figure 14. Molecular structures of 12 and 13 [12].

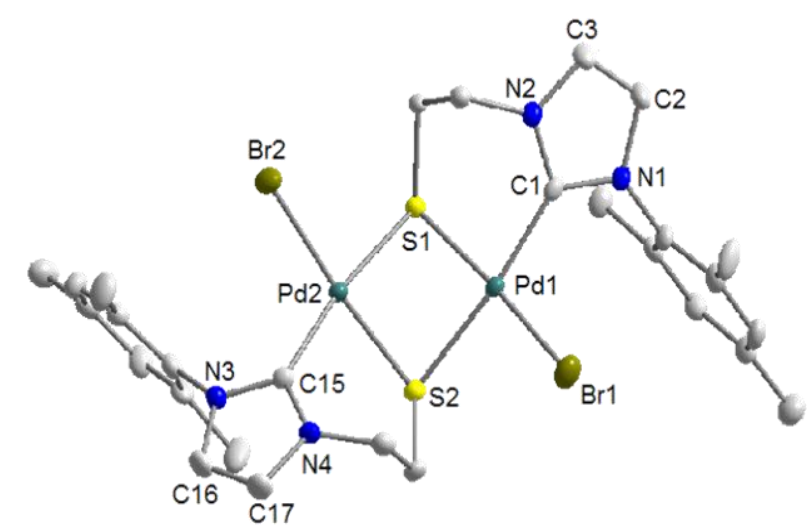

12

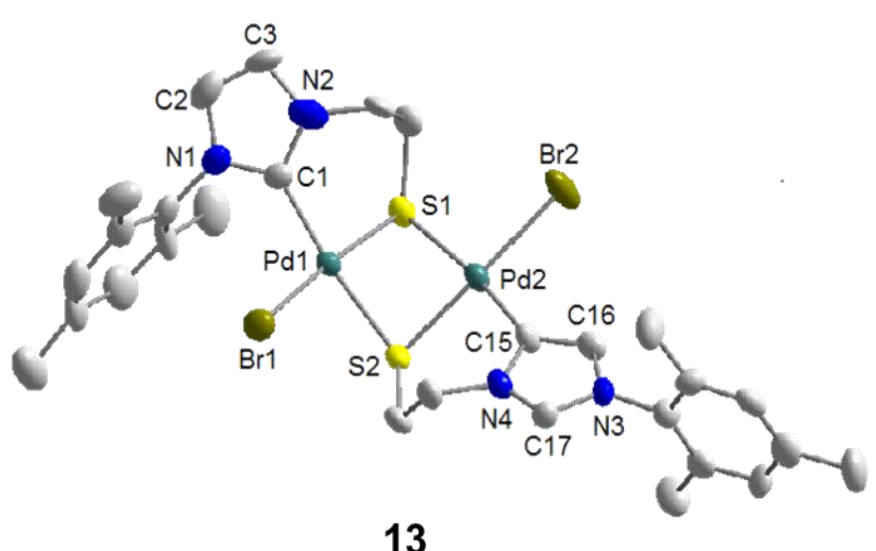

13

\subsection{Reactivity Studies with Ag-carboxylates}

In order to investigate the robustness of the $\left[\mathrm{Pd}_{2} \mathrm{~S}_{2}\right]$ core of $\mathbf{1 1}$ and $\mathbf{1 2}$, attempts were made to alkylate the thiolato-bridges [11], to expose the compound to Ag-salts [11] or to treat the complex with external thiolato ligands [12].

The metathesis reaction of mixed halo/NHC $\mathrm{Pd}(\mathrm{II})$ complexes with Ag-carboxylates is an established method to synthesize mixed carboxylato-carbene complexes as potentially useful catalyst precursors [23,24]. Complex 11 was reacted with 2 equiv of $\mathrm{AgO}_{2} \mathrm{CCF}_{3}$ in $\mathrm{CH}_{3} \mathrm{CN}$ (Figure 15), which cleanly afforded the dinuclear, mixed carbene-carboxylato $\mathrm{Pd}(\mathrm{II})$ complex $\left[\mathrm{Pd}\left(\mathrm{O}_{2} \mathrm{CCF}_{3}\right)\left({ }^{\mathrm{B}} \mathbf{Q}-\kappa^{2} C, \mu-S\right)\right]_{2}$ (14) in quantitative yield without affecting the $\left[\mathrm{Pd}_{2} \mathrm{~S}_{2}\right]$ core [11]. Although the potential interaction of 
the soft sulfur donor with the soft $\mathrm{Ag}(\mathrm{I})$ ion could compete with the desired halide abstraction, the bridging mode of the thiolato-donor efficiently reduces the number of lone-pairs available at sulfur, which prevents the interference with silver. The solid state structure of $\mathbf{1 4}$ confirms that both bromido ligands in $\mathbf{1 1}$ have been replaced by trifluoroacetato ligands with the $\left[\mathrm{Pd}_{2} \mathrm{~S}_{2}\right]$ core remaining intact (Figure 15).

Figure 15. Synthesis of $\operatorname{Pd}(\mathrm{II})$ trifluoroacetato complex 14 and its molecular structure [11].
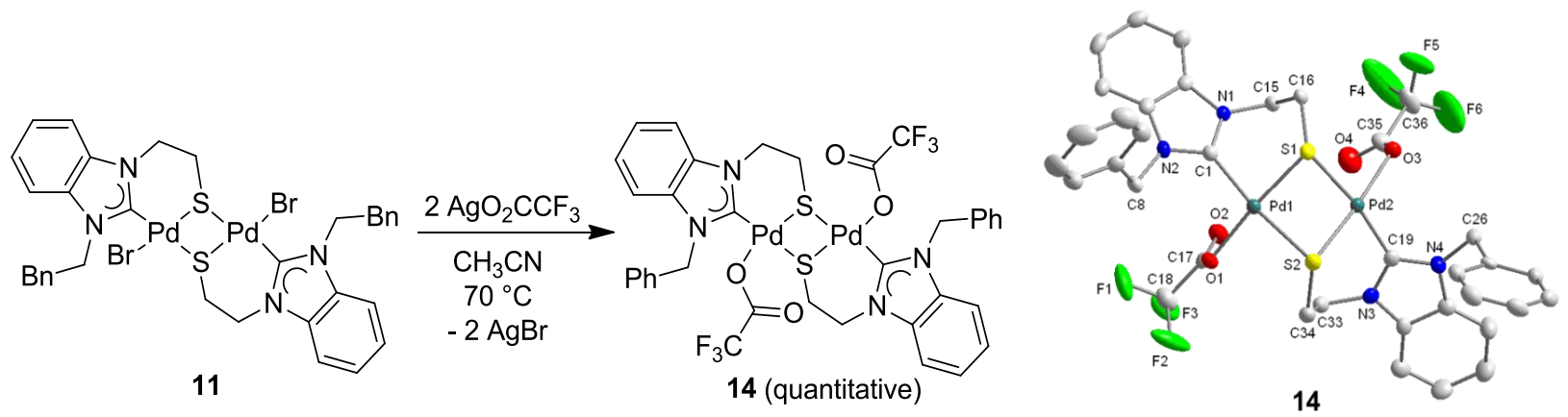

\subsection{Reactivity Studies with Alkylating Reagents}

The successful S-alkylation of thiolato-bridged complexes of type $\mathbf{1 1}$ would allow for a convenient template-directed synthesis of thioether-functionalized NHC complexes. Thus, a series of electrophiles, including iodomethane and dimethylsulfate, has been used in an attempt to alkylate the sulfur atoms of dimer 11, however to no avail, and only starting materials were re-isolated. Again the lower electron density at the sulfur atoms as a result of the bridging mode may be the reason that prevents their alkylation. Unexpectedly, the reaction of $\mathbf{1 1}$ with an excess of the strong alkylating agent $\mathrm{Me}_{3} \mathrm{OBF}_{4}$ led to the formation of the novel tetranuclear complex $\left[\mathrm{Pd}_{4} \mathrm{Br}_{2}\left({ }^{\mathrm{B}} \mathbf{Q}-\kappa^{2} C, \mu-S\right)_{4}\right]\left(2 \mathrm{BF}_{4}\right)$ (15) (Scheme 13) [11]. Apparently, electrophilic attack occurred preferably at the bromido ligand, supposedly liberating $\mathrm{CH}_{3} \mathrm{Br}$ and resulting in a rearrangement of the unsaturated complex fragments to tetranuclear $\mathbf{1 5}$.

Scheme 13. Synthesis of tetranuclear complex 15 [11].

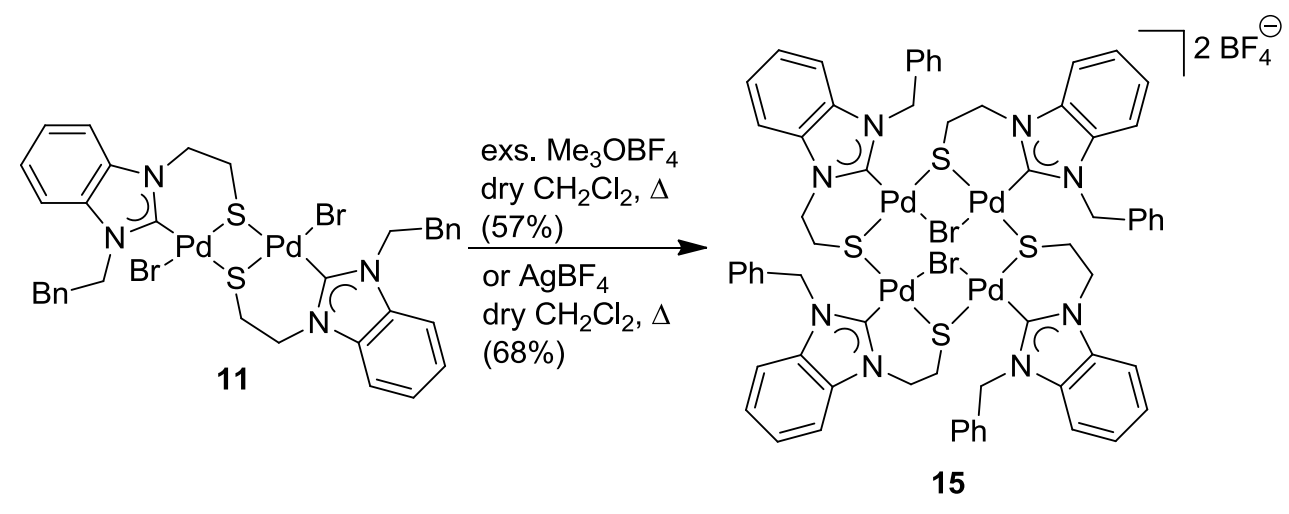

To verify the unusual role of $\mathrm{Me}_{3} \mathrm{OBF}_{4}$ as a halide-abstracting agent, $\mathbf{1 1}$ was treated with one equiv of $\mathrm{AgBF}_{4}$. Indeed, this reaction furnished complex 15 as well. Consequently, $\mathrm{Me}_{3} \mathrm{OBF}_{4}$ can be regarded as a very useful metal-free alternative to the commonly used Ag- and toxic Tl-based reagents. 
The molecular structure of $\mathbf{1 5}$ shows an eight-membered square consisting of alternating four palladium and four sulfur atoms with dimensions of 4.653(5) $\AA$ × 4.662(5) $\AA$ (Figure 16). Each of the four $\mathrm{Pd}(\mathrm{II})$ centers is coordinated by one carbene, one $\mu$-bromido, and two $\mu$-thiolato ligands in a square-planar fashion. Two carbene moieties are each found above and below the $\left[\mathrm{Pd}_{4} \mathrm{~S}_{4}\right]$ macrocycle, and consequently, the two bridging bromido ligands trans to the carbenes are found at opposite sides.

Figure 16. Molecular structures of tetranuclear complexes 15 and 16 [12].
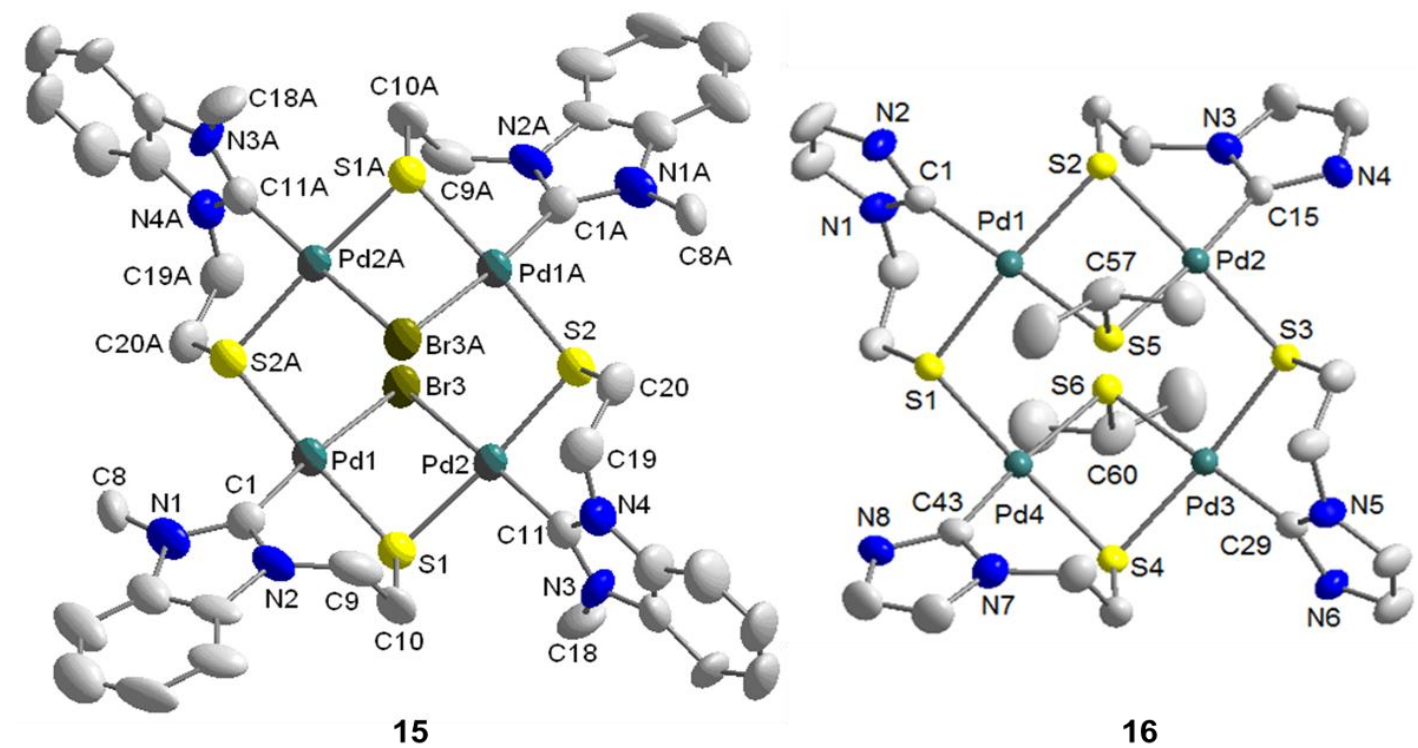

16

\subsection{Reactivity Studies with External Thiolato Ligands}

The imidazolin-2-ylidene complex 12 was treated with two equiv of in situ generated sodium isopropyl thiolate. Initially, a simple bromido-thiolato ligand exchange was expected. Although the bromido ligands were indeed abstracted, a tetra-palladium species formed instead [12]. Reaction optimization via counter anion exchange using $\mathrm{NaBF}_{4}$ resulted in the isolation of the tetranuclear $\left[\mathrm{Pd}_{4} \mathrm{~S}_{4}\right]$ macrocyclic compound $\left[\mathrm{Pd}_{4}\left\{\mathrm{SCH}\left(\mathrm{CH}_{3}\right)_{2}\right\}_{2}\left({ }^{\mathrm{I}} \mathbf{R}-\kappa^{2} C, \mu-S\right)_{4}\right]\left(2 \mathrm{BF}_{4}\right)$ (16) (Scheme 14). Seemingly, the bromido ligand in $\mathbf{1 2}$ was first replaced with one isopropyl thiolato ligand accompanied by the precipitation of $\mathrm{NaBr}$. The new highly nucleophilic thiolato ligand replaces a 2 nd bromido ligand of another $\mathrm{Pd}(\mathrm{II})$ center leading to a rearrangement of one $\mathrm{Pd}-\mathrm{S}$ bond and subsequent dimerization to yield tetranuclear $\mathbf{1 6 .}$

Scheme 14. Synthesis of tetranuclear complex 16 [12].

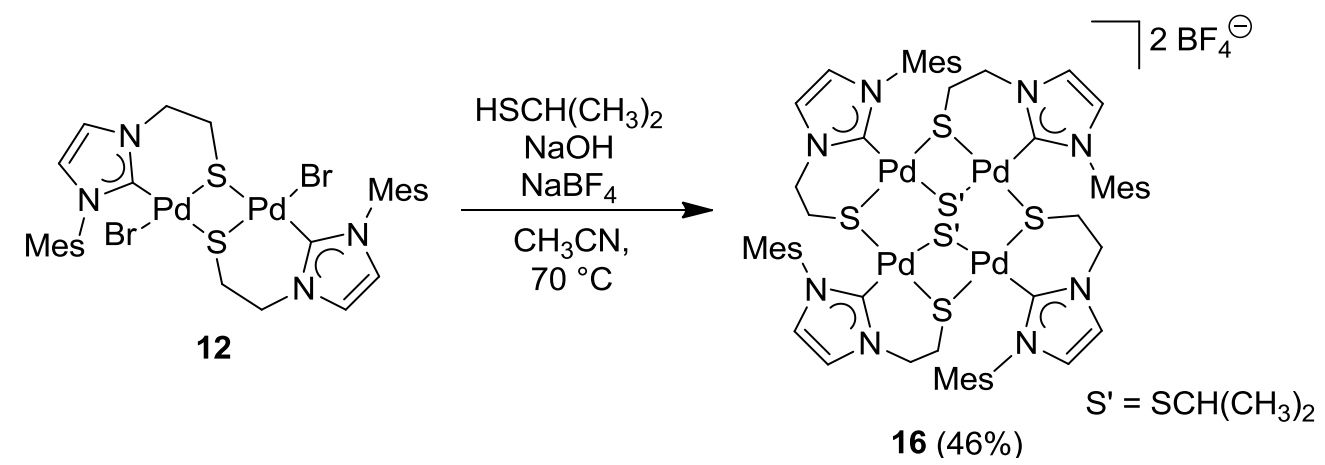


As shown by the molecular structure of 16, each $\mathrm{Pd}(\mathrm{II})$ center is surrounded by one carbene and three $\mu$-thiolato donors in a square-planar fashion (Figure 16). Similar to the tetranuclear complex 15, there is an eight-membered $\left[\mathrm{Pd}_{4} \mathrm{~S}_{4}\right]$ macrocycle with almost the same dimensions of [4.6421(24) $\AA \mathrm{x}$ $4.6617(24) \AA]$. The two bridging isopropyl thiolato groups are located at different sides of the macrocycle.

\section{Catalytic Applications}

Despite the fact that sulfur functions are generally regarded as catalyst poisons [25], transition metal complexes with sulfur donors have found applications in catalyzing various reactions, such as allylic alkylations [26-28], hydroformylations [29], hydrogenations [30-32] and C-C coupling reaction [33]. In order to evaluate the catalytic activities of Pd(II) complexes bearing sulfur-functionalized NHCs, selected compounds synthesized in our study have been tested in Suzuki-Miyaura, Mizoroki-Heck, and hydroamination reactions.

Table 1. Suzuki-Miyaura coupling reactions ${ }^{a}$ catalyzed by complexes 11, 14, and 15 [11].

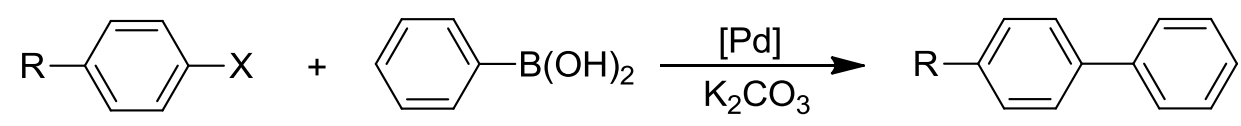

$$
\begin{aligned}
& \mathrm{R}=\mathrm{NO}_{2}, \mathrm{CN}, \mathrm{CHO}, \mathrm{CH}_{3}, \mathrm{OCH}_{3}, \mathrm{Cl}, \mathrm{COCH}_{3} \\
& \mathrm{X}=\mathrm{Br}, \mathrm{Cl}
\end{aligned}
$$

\begin{tabular}{|c|c|c|c|c|c|c|c|c|}
\hline Entry & Catalyst & $\begin{array}{c}\text { temp. } \\
{\left[{ }^{\circ} \mathbf{C}\right]}\end{array}$ & Aryl halide & $\begin{array}{l}\text { catalyst } \\
\text { loading } \\
{[\mathrm{mol} \%]}\end{array}$ & $\begin{array}{c}\mathbf{t} \\
{[\mathrm{h}]}\end{array}$ & $\begin{array}{c}\text { yield } \\
{\left[^{[}\right]^{b}}\end{array}$ & TON & $\begin{array}{l}\text { TOF } \\
{\left[h^{-1}\right]}\end{array}$ \\
\hline $1^{c}$ & 11 & 60 & 4-bromobenzophenone & 0.001 & 24 & 0 & 0 & 0 \\
\hline 2 & 11 & 60 & 4-bromobenzophenone & 0.001 & 24 & 84 & 84,000 & 3500 \\
\hline 3 & 14 & 60 & 4-bromobenzophenone & 0.001 & 24 & $>99$ & 100,000 & 4167 \\
\hline 4 & $15^{d}$ & 60 & 4-bromobenzophenone & 0.001 & 24 & 48 & 96,000 & 4000 \\
\hline 5 & 14 & 60 & 4-bromobenzonitrile & 0.001 & 24 & $>99$ & 100,000 & 4167 \\
\hline 6 & 14 & 60 & 1-bromo-4-nitrobenzene & 0.001 & 42 & 90 & 90,000 & 2143 \\
\hline 7 & 14 & 80 & 4-bromobenzaldehyde & 0.001 & 23 & $>99$ & 100,000 & 4167 \\
\hline 8 & 14 & 100 & 2,6-dibromopyridine ${ }^{e}$ & 0.0025 & 48 & $>99$ & 20,000 & 417 \\
\hline 9 & 14 & 100 & 4-bromotoluene & 0.0025 & 20 & 97 & 38,800 & 1940 \\
\hline 10 & 14 & 100 & 4-bromoanisole & 0.0025 & 24 & 86 & 34,400 & 1433 \\
\hline 11 & 14 & 100 & 1-bromo-4-chlorobenzene & 0.0025 & 24 & $72^{f}$ & 28,800 & 1200 \\
\hline $12^{g}$ & 14 & 100 & 4-chlorobenzaldehyde & 0.1 & 72 & 41 & 410 & 5.7 \\
\hline
\end{tabular}

${ }^{a}$ Reaction conditions: $1 \mathrm{mmol}$ of aryl halide; $1.4 \mathrm{mmol}$ of phenylboronic acid; $1.4 \mathrm{mmol}$ of $\mathrm{K}_{2} \mathrm{CO}_{3} ; 1 \mathrm{~mL}$ of $\mathrm{H}_{2} \mathrm{O}$; the desired amount of precatalyst. ${ }^{b}$ Yields were determined by ${ }^{1} \mathrm{H}$ NMR spectroscopy for an average of two runs. ${ }^{c}$ The solvent is $1 \mathrm{~mL}$ of dioxane. ${ }^{d} 0.0005 \mathrm{~mol} \%$ of $15{ }^{e} 0.5 \mathrm{mmol}$ of 2,6-dibromopyridine. ${ }^{f}$ isolated yield. ${ }^{g}$ With addition of 1.0 equiv of $\left[\mathrm{N}\left(n-\mathrm{C}_{4} \mathrm{H}_{9}\right)_{4}\right] \mathrm{Br}$. 


\subsection{Suzuki-Miyaura Coupling Reactions}

The thiolato-bridged dimeric complex 11 was first tested in Suzuki-Miyaura coupling of 4-bromoacetophenone and phenylboronic acid at low catalyst loading $(0.001 \mathrm{~mol} \%)$ in $\mathrm{H}_{2} \mathrm{O}$ or dioxane. $\mathrm{H}_{2} \mathrm{O}$ proved to be a superior solvent as higher yields were obtained even under mild conditions (Table 1, entry 1 and 2), which is in line with previous findings [34-37]. A comparative study on the thiolato-NHC complexes 11, 14 and 15 revealed that 14 bearing labile trifluoroacetato ligands was the best precatalyst (entries 2-4).

In order to gain more insights into the catalytic behavior of $\mathbf{1 4}$, a more detailed kinetic study was carried out on the coupling of 4-bromoacetophenone and phenylboronic acid. The concentration/time profile showed that the reaction experienced a long induction period of about $22 \mathrm{~h}$ before the rate increased exponentially leading to complete conversion within $2 \mathrm{~h}$ (Figure 17). A dimer-monomer equilibrium [38] before catalyst initiation was proposed to be responsible for the long induction time. Furthermore, the shape of the reaction profile suggested the involvement of various catalytically active species prior to the formation of the most active catalyst.

Figure 17. Concentration/time diagram [yield (\%), time (h)] for the Suzuki-Miyaura coupling reaction of 4-bromoacetophenone and phenylboronic acid catalyzed by 14 [11].

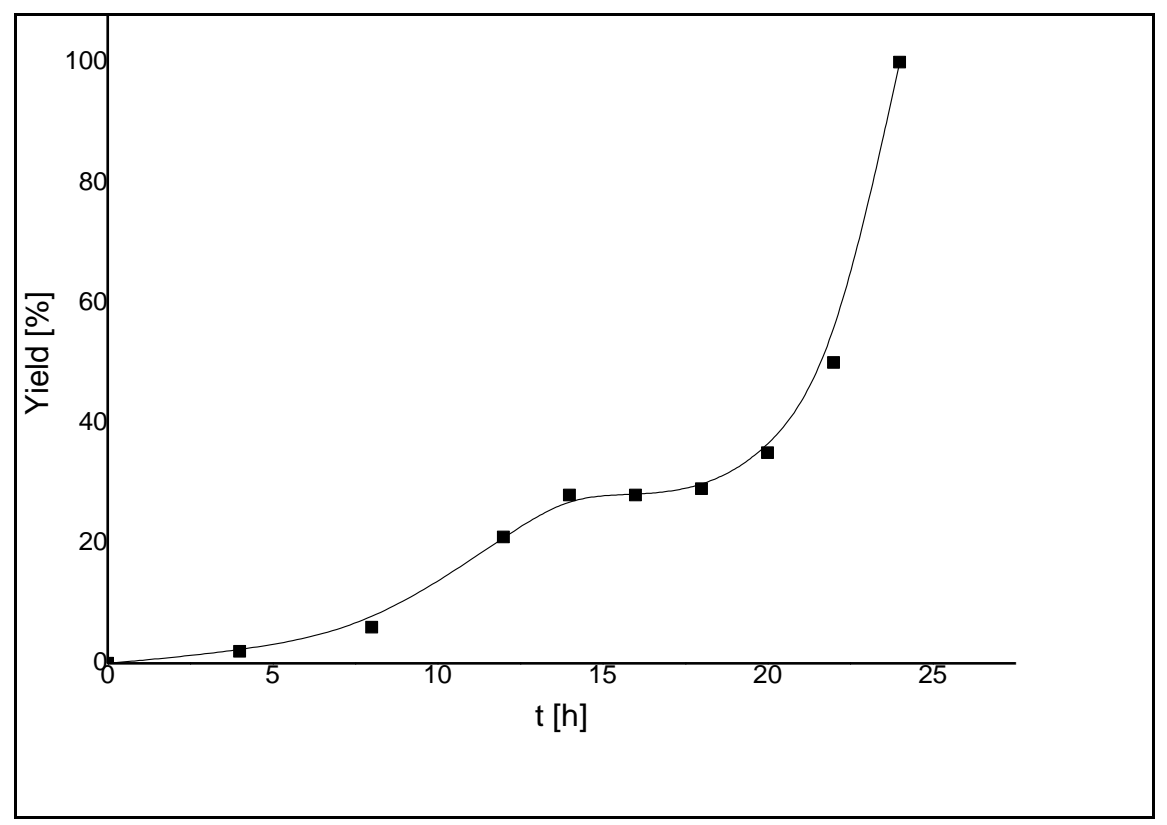

The couplings of phenylboronic acid with various aryl halides catalyzed by $\mathbf{1 4}$ were also studied. With aryl bromides, including 2,6-dibromopyridine, good yields were achieved (entries 5-11), whereas only a moderate yield was obtained with 4-chlorobenzaldehyde (entry 12).

In order to compare the catalytic activities of both bis- versus mono-NHC complexes, selected S-Me functionalized complexes cis-1a, trans-1a, cis-2a, $\mathbf{3}$ and $\mathbf{4}$ were also tested in aqueous SuzukiMiyaura couplings. These reactions gave good yields in the couplings of aryl bromides (Table 2), while only moderate to low results were obtained for chloro-substrates. Moreover, it was found that among bis(carbene) species, cis-1a and cis-2a performed slightly better than the trans-isomer trans-1a. The necessity for trans-1a to isomerize to its cis analogue during catalysis may account for the 
superior of cis-isomers [39]. However, the mixed NHC-phosphine complex $\mathbf{4}$ proved to be the most active. The thiophene-functionalized benzimidazolin-2-ylidene complex cis-17 showed similar activities to those of the aforementioned bis(carbene) complexes in aqueous Suzuki-Miyaura reactions under identical conditions (Table 2, entries 6, 12, 18, 24, 30).

Table 2. Suzuki-Miyaura coupling reactions ${ }^{a}$ catalyzed by $\mathbf{1 a}$, cis-2a, 3, $\mathbf{4}$ and cis-17 $[8,13]$.

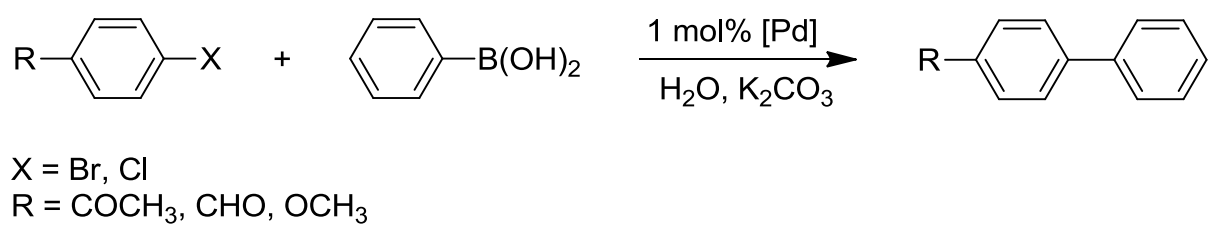

\begin{tabular}{|c|c|c|c|c|c|}
\hline Entry $^{a}$ & Catalyst & Aryl halide & $\mathbf{t}[\mathbf{h}]$ & temp. $\left[{ }^{\circ} \mathrm{C}\right]$ & yield $[\%]^{b}$ \\
\hline 1 & $c i s-\mathbf{1 a}$ & \multirow{6}{*}{$-1 \geqslant-\mathrm{Cr}$} & \multirow{6}{*}{8} & \multirow{6}{*}{ RT } & $>99$ \\
\hline 2 & trans $\mathbf{- 1 a}$ & & & & $>99$ \\
\hline 3 & $c i s-\mathbf{2 a}$ & & & & $>99$ \\
\hline 4 & 3 & & & & $>99$ \\
\hline 5 & 4 & & & & $>99$ \\
\hline 6 & cis-17 & & & & $>99$ \\
\hline 7 & $c i s-\mathbf{1 a}$ & & \multirow{6}{*}{8} & \multirow{6}{*}{ RT } & 98 \\
\hline 8 & trans-1a & & & & 84 \\
\hline 9 & $c i s-\mathbf{2 a}$ & & & & 90 \\
\hline 10 & 3 & & & & 85 \\
\hline 11 & 4 & & & & $>99$ \\
\hline 12 & cis-17 & & & & 85 \\
\hline $13^{c}$ & cis-1a & \multirow{6}{*}{$\mathrm{Br} \longrightarrow \mathrm{OC}$} & \multirow{6}{*}{21} & \multirow{6}{*}{85} & $>99$ \\
\hline $14^{c}$ & trans-1a & & & & $>99$ \\
\hline $15^{c}$ & $\operatorname{cis}-\mathbf{2 a}$ & & & & $>99$ \\
\hline $16^{c}$ & 3 & & & & $>99$ \\
\hline $17^{c}$ & 4 & & & & $>99$ \\
\hline $18^{c}$ & cis-17 & & & & $>99$ \\
\hline $19^{c}$ & $c i s-\mathbf{1 a}$ & \multirow{6}{*}{$\mathrm{Cl} \longrightarrow \mathrm{Cr}$} & \multirow{6}{*}{21} & \multirow{6}{*}{85} & 7 \\
\hline $20^{c}$ & trans-1a & & & & 11 \\
\hline $21^{c}$ & $c i s-\mathbf{2 a}$ & & & & 3 \\
\hline $22^{c}$ & 3 & & & & 8 \\
\hline $23^{c}$ & 4 & & & & 52 \\
\hline $24^{c}$ & cis-17 & & & & 9 \\
\hline $25^{c}$ & cis-1a & & \multirow{6}{*}{21} & \multirow{6}{*}{85} & 3 \\
\hline $26^{c}$ & trans-1a & & & & 9 \\
\hline $27^{c}$ & $c i s-\mathbf{2 a}$ & & & & 23 \\
\hline $28^{c}$ & 3 & & & & 25 \\
\hline $29^{c}$ & 4 & & & & 44 \\
\hline $30^{c}$ & cis-17 & & & & 14 \\
\hline
\end{tabular}

${ }^{a}$ Reaction conditions: $1 \mathrm{mmol}$ of aryl halide; $1.5 \mathrm{mmol}$ of phenylboronic acid; $3 \mathrm{~mL}$ of water; 2 equivalents of $\mathrm{K}_{2} \mathrm{CO}_{3} ; 1 \mathrm{~mol} \%$ of precatalyst. ${ }^{b}$ Yields were determined by ${ }^{1} \mathrm{H}-\mathrm{NMR}$ spectroscopy for an average of two runs. ${ }^{c}$ With addition of 1.5 equivalents of $\left[\mathrm{N}\left(n-\mathrm{C}_{4} \mathrm{H}_{9}\right)_{4}\right] \mathrm{Br}$. 


\subsection{Mizoroki-Heck Coupling Reactions}

The benzimidazolin-2-ylidene CSC-pincer type Pd(II) complexes were tested in Mizoroki-Heck reactions. Pseudo-pincer complexes 5 and $\mathbf{6}$ as well as pincer complex $\mathbf{7}$ were found to be highly active in catalyzing the couplings of a range of activated substrates (Table 3, entries 1-15).

Table 3. Mizoroki-Heck coupling reactions ${ }^{a}$ catalyzed by complexes 5-7 [9].<smiles>[R]Oc1ccc(Br)cc1</smiles><smiles>[R]c1ccc(/C=C/C(=O)OC(C)(C)C)cc1</smiles><smiles>C=CC(=O)OC(C)(C)C</smiles>

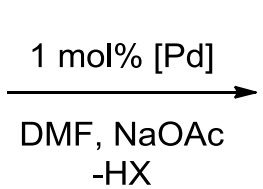<smiles>CC(C)(C)OC(=O)/C=C/c1cccc(/C=C/C(=O)OC(C)(C)C)n1</smiles>
$\mathrm{R}=\mathrm{NO}_{2}, \mathrm{CHO}, \mathrm{CN}, \mathrm{CH}_{3} \mathrm{CO}, \mathrm{Cl}, \mathrm{CH}_{3}, \mathrm{OCH}_{3}$

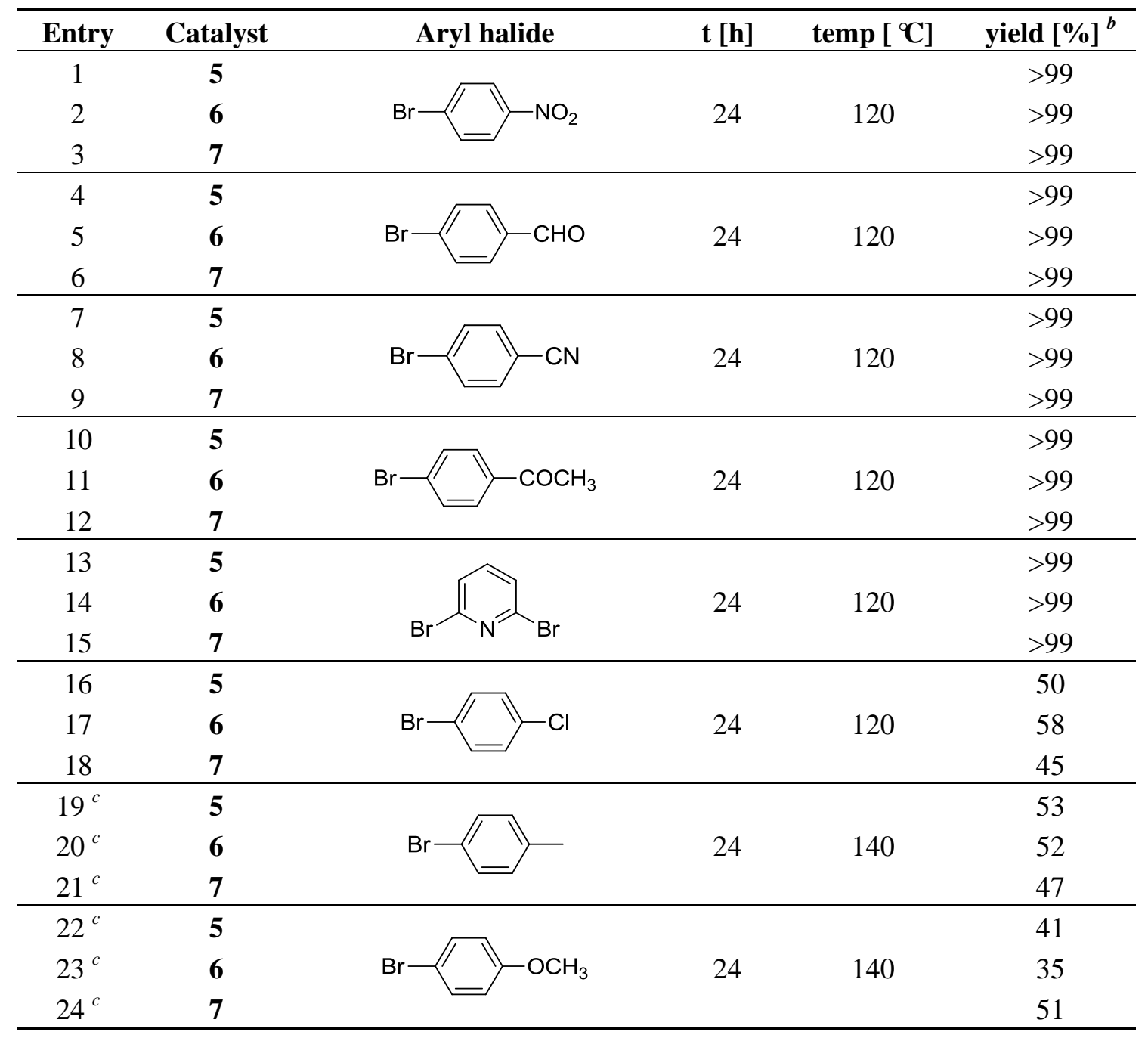

${ }^{a}$ Reaction conditions: $1 \mathrm{mmol}$ of aryl halide $(0.5 \mathrm{mmol}$ of 2,6-dibromopyridine); $1.4 \mathrm{mmol}$ of tert-butyl acrylate; $3 \mathrm{~mL}$ of DMF; $1.5 \mathrm{mmol}$ of NaOAc; $1 \mathrm{~mol} \%$ of precatalyst. ${ }^{b}$ Yields were determined by ${ }^{1} \mathrm{H}$ NMR spectroscopy for an average of two runs. ${ }^{c}$ With addition of 1.5 equiv of $\left[\mathrm{N}\left(n-\mathrm{C}_{4} \mathrm{H}_{9}\right)_{4}\right] \mathrm{Br}$. 
Complex 7 could still give quantitative yield with a loading of as low as $10^{-3}$ mol\% in the coupling of 4-bromobenzaldehyde. However, only poor to moderate yields were obtained with deactivated aryl bromides (Table 3, entries 16-24). Notably, a comparison did not reveal the superiority of any complex. It was anticipated that all three complexes decomposed to palladium nanoparticles of very similar size that do the catalytic work.

\subsection{Hydroamination of Alkynes}

The imidazole-based CSC-pincer type Pd(II) complexes, on the other hand, were studied in hydroamination reactions. The direct addition of a primary or secondary amine to a double or triple bond is a reaction of $100 \%$ atom efficiency, which is highly desirable and consistent with the current development of "greener" methodologies [40,41]. Since the investigations on Pd(II) NHC complexes catalyzed hydroaminations are rare [42-44], complexes 8-10 were studied in the intermolecular hydroamination reaction of phenylacetylene with various anilines.

Table 4. Hydroamination reactions ${ }^{a}$ catalyzed by complexes $\mathbf{8}-\mathbf{1 0}$ [10].

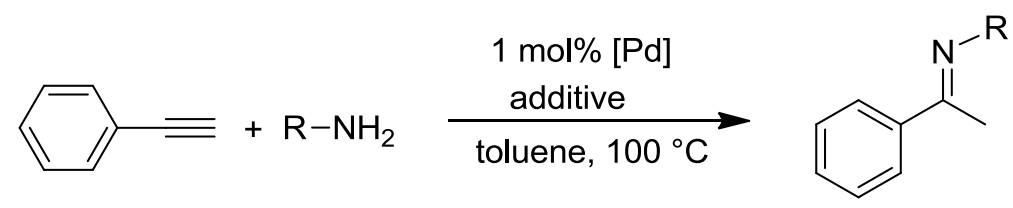

\begin{tabular}{|c|c|c|c|c|}
\hline Entry & Aniline & $\begin{array}{c}\text { complex } 8 \\
\text { yield }^{b}\end{array}$ & $\begin{array}{c}\text { complex } 9 \\
\text { yield }^{b}\end{array}$ & $\begin{array}{c}\text { complex } 10 \\
\text { yield }^{b}\end{array}$ \\
\hline 1 & & - & $87^{c}$ & - \\
\hline 2 & & 55 & 94 & 53 \\
\hline 3 & & - & $0^{d}$ & - \\
\hline 4 & & 43 & 75 & 53 \\
\hline 5 & & 39 & 58 & 42 \\
\hline 6 & & 26 & 48 & 35 \\
\hline 7 & & 22 & 51 & 28 \\
\hline 8 & & 23 & 30 & 20 \\
\hline
\end{tabular}

${ }^{a}$ Reaction conditions: $1.0 \mathrm{mmol}$ of phenylacetylene; $0.5 \mathrm{mmol}$ of aniline; $1 \mathrm{~mL}$ of toluene; $5 \mathrm{~mol} \%$ of triflic acid; 1 mol\% of precatalyst. ${ }^{b}$ Yields were determined by GC-MS by using $n$-hexadecane as internal standard for an average of two runs. ${ }^{c}$ With addition of $10 \mathrm{~mol} \%$ of triflic acid. ${ }^{d}$ Without addition of triflic acid. 
A benchmark reaction with 2,6-dimethylaniline and $1 \mathrm{~mol} \%$ of 9 showed that $5 \mathrm{~mol} \%$ triflic acid was essential to get a good result (Table 4, entries 1-3). An extensive study on different anilines and catalysts revealed that good to moderate yields were obtained with mesitylaniline and phenylacetylene, and complex 9 outperformed $\mathbf{8}$ and 10 (entries 2 and 4). However, reactions with 2,6-diisopropylaniline, 2,3-dimethylaniline, 2-methylaniline, and the parent aniline gave only poor yields, indicating that anilines with intermediate steric bulk are best for this reaction (entries 5-8).

\section{Conclusions and Outlook}

A series of $\mathrm{Pd}(\mathrm{II})$ complexes bearing NHCs with different sulfur-functions, i.e., thioether, sulfoxide, thiolato, and thiophene, have been synthesized. Experimental evidence for a true hemilabile coordination behavior was obtained using a thioether-NHC complex. Complexes with more rigid CSCpincer type ligands have also been synthesized, and the reasons governing the pincer versus pseudopincer formation have been investigated. Incorporation of the thiolato function into $\mathrm{Pd}(\mathrm{II})$ complexes resulted in a diverse coordination chemistry giving rise to both dinuclear and tetranuclear complexes. The catalytic activities of selected complexes have been studied in Mizoroki-Heck, Suziki-Miyaura, and hydroamination reactions. Future studies may focus on complexation of these sulfurfunctionalized ligands with other metal centers, e.g., $\mathrm{Ni}(\mathrm{II}), \mathrm{Pt}(\mathrm{II})$, and $\operatorname{Ir}(\mathrm{I})$, which should lead to complexes with enhanced structural diversities and interesting properties with potential applications in metallo-based supramolecular chemistry and catalysis.

\section{Acknowledgments}

We thank all co-workers for their enthusiasm and efforts in developing this chemistry. Financial support (WBS R-143-000-407-112) from the National University of Singapore and technical assistance from the CMMAC staff of our department are gratefully acknowledged.

\section{References}

1. Hahn, F.E.; Jahnke, M.C. Heterocyclic carbenes: Synthesis and coordination chemistry. Angew. Chem. Int. Ed. 2008, 47, 3122-3172.

2. Kühl, O. The Chemistry of functionalised $N$-heterocyclic carbenes. Chem. Soc. Rev. 2007, 36, 592-607.

3. Normand, A.T.; Cavell, K.J. Donor-functionalised $N$-heterocyclic carbene complexes of group 9 and 10 metals in catalysis: Trends and directions. Eur. J. Inorg. Chem. 2008, 2781-2800.

4. John, A.; Ghosh, P. Fascinating Frontiers of N/O-Functionalized N-Heterocyclic Carbene Chemistry: From chemical catalysis to biomedical applications. Dalton Trans. 2010, 39, 7183-7206.

5. Braunstein, P.; Naud, F. Hemilability of Hybrid Ligands and the Coordination Chemistry of Oxazoline-Based Systems. Angew. Chem. Int. Ed. 2001, 40, 680-699.

6. Bierenstiel, M.; Cross, E.D. Sulfur-Functionalized N-Heterocyclic Carbenes and Their Transition Metal Complexes. (References therein). Coord. Chem. Rev. 2011, 255, 574-590. 
7. Huynh, H.V.; Yeo, C.H.; Tan, G.K. Hemilabile Behavior of a Thioether-Functionalized N-Heterocyclic Carbene Ligand. Chem. Commun. 2006, 3833-3835.

8. Huynh, H.V.; Yeo, C.H.; Chew, Y.X. Syntheses, Structures, and Catalytic Activities of Hemilabile Thioether-Functionalized NHC Complexes. Organometallics 2010, 29, 1479-1486.

9. Huynh, H.V.; Yuan, D.; Han, Y. Syntheses and Catalytic Activities of Pseudo-Pincer and CSC Pincer-Type Pd(II) Complexes Derived from Benzannulated N-Heterocyclic Carbenes. Dalton Trans. 2009, 7262-7268.

10. Yuan, D.; Tang, H.; Xiao, L.; Huynh, H.V. CSC-pincer versus Pseudo-Pincer Complexes of Palladium(II): a Comparative Study on Complexation and Catalytic Activities of NHC Complexes. Dalton Trans. 2011, 40, 8788-8795.

11. Yuan, D.; Huynh, H.V. Dinuclear and Tetranuclear Palladium(II) Complexes of a ThiolatoFunctionalized, Benzannulated $N$-Heterocyclic Carbene Ligand and Their Activities Toward Suzuki-Miyaura Coupling. Organometallics 2010, 29, 6020-6027.

12. Yuan, D.; Huynh, H.V. Syntheses and Characterizations of Thiolato-Functionalized N-Heterocyclic Carbene Pd(II) Complexes with Normal and Mesoionic Binding Modes. Dalton Trans. 2011, 40, 11698-11703.

13. Huynh, H.V.; Chew, Y.X. Synthesis, Structural Characterization and Catalytic Activity of a Palladium(II) Complex Bearing a New Ditopic Thiophene-N-Heterocyclic Carbene Ligand. Inorg. Chim. Acta 2010, 363, 1979-1983.

14. Liu, S.; Lee, C.; Fu, C.; Chen, C.; Liu, Y.; Elsevier, C.J.; Peng, S.; Chen, J. N-Heterocyclic Carbene Transfer from Gold(I) to Palladium(II). Organometallics 2009, 28, 6957-6962.

15. Lin, J.C.Y.; Huang, R.T.W.; Lee, C.S.; Bhattacharyya, A.; Hwang, W.S.; Lin, I.J.B. Coinage Metal-N-Heterocyclic Carbene Complexes. Chem. Rev. 2009, 109, 3561-3598.

16. Slagt, M.Q.; van Zwieten, D.A.P.; Moerkerk, A.J.C.M.; Gebbink, R.J.M.K.; van Koten, G. NCN-Pincer Palladium Complexes with Multiple Anchoring Points for Functional Groups. Coord. Chem. Rev. 2004, 248, 2275-2282.

17. Pugh, D.; Danopoulos, A.A. Metal Complexes with 'Pincer'-Type Ligands Incorporating N-Heterocyclic Carbene Functionalities. Coord. Chem. Rev. 2007, 251, 610-641.

18. Huynh, H.V.; Han, Y.; Jothibasu, R.; Yang, J.A. ${ }^{13}$ C NMR Spectroscopic Determination of Ligand Donor Strengths Using N-Heterocyclic Carbene Complexes of Palladium(II). Organometallics 2009, 28, 5395-5404.

19. Sellmann, D.; Geipel, F.; Heinemann, F.W. Mononuclear Carbene Dithiolate [Ni(NHX)(' $\left.\left.\mathrm{S}_{2} \mathrm{C}^{\prime}\right)\right]$ Complexes with $\mathrm{HNX}=\mathrm{HNPiPr}{ }_{3}$ or $\mathrm{HNSPh}_{2}$ Coligands $\left({ }^{2} \mathrm{~S}_{2} \mathrm{C}^{\prime 2-}=1,3\right.$-Imidazolidinyl- $N$, $N$ '-bis(2benzenethiolate)(2-)). Z. Anorg. Allg. Chem. 2001, 627, 1034-1038.

20. Cabeza, J.A.; del Rio, I.; Sánchez-Vega, M.G.; Suárez, M. Methyl Levamisolium Triflate as a Precursor to a Chiral Bifunctional N-Heterocyclic Carbene-Thiolate Ligand: Palladium(II) Complexes. Organometallics 2006, 25, 1831-1834.

21. Iwasaki, F.; Yasui, M.; Yoshida, S.; Nishiyama, H.; Shimamoto, S.; Matsumura, N. Crystal and Molecular Structures of Novel Metal-Carbene Complexes III. Rh-Carbene Complexes and $\mathrm{Cu}$ Complex. B. Chem. Soc. Jpn. 1996, 69, 2759-2770.

22. Guisado-Barrios, G.; Bouffard, J.; Donnadieu, B.; Bertrand, G. Crystalline 1H-1,2,3-triazol-5ylidenes: New Stable Mesoionic Carbenes (MICs). Angew. Chem. Int. Ed. 2010, 49, 4759-4762. 
23. Huynh, H.V.; Jothibasu, R. Dipalladium Bis( $\mu$-isopropylthiolato) Complexes with a $\left[\mathrm{Pd}_{2} \mathrm{~S}_{2}\right]$ Core Supported by N-Heterocyclic Carbenes. Organometallics 2007, 26, 6852-6856.

24. Yuan, D.; Huynh, H.V. 1,2,3-Triazolin-5-ylidenes: Synthesis of Hetero-bis(carbene) Pd(II) Complexes, Determination of Donor Strengths, and Catalysis. Organometallics 2012, 31, 405-412.

25. Dunleavy, J.K. Sulfur as a Catalyst Poison. Platinum Metals Rev. 2006, 50, 110.

26. Evans, D.A.; Campos, K.R.; Tedrow, J.S.; Michael, F.E.; Gagné, M.R. Application of Chiral Mixed Phosphorus/Sulfur Ligands to Palladium-Catalyzed Allylic Substitutions. J. Am. Chem. Soc. 2000, 122, 7905-7920.

27. Barbaro, P.; Currao, A.; Herrmann, J.; Nesper, R.; Pregosin P.S.; Salzmann, R. Chiral P,S-Ligands Based on $\beta$-D-Thioglucose Tetraacetate. Palladium(II) Complexes and Allylic Alkylation. Organometallics 1996, 15, 1879-1888.

28. Herrmann, J.; Pregosin, P.S.; Salzmann, R. Palladium $\pi$-Allyl Chemistry of New P,S Bidentate Ligands. Selective but Variable Dynamics in the Isomerization of the $\eta^{3}-\mathrm{C}_{3} \mathrm{H}_{5}$ and $\eta^{3}$-PhCHCHCHPh $\pi$-Allyl Ligands. Organometallics 1995, 14, 3311-3318.

29. Pàmies, O.; Diéguez, M.; Net, G.; Ruiz, A.; Claver, C. Synthesis and Coordination Chemistry of Novel Chiral P,S-Ligands with a Xylofuranose Backbone: Use in Asymmetric Hydroformylation and Hydrogenation. Organometallics 2000, 19, 1488-1496.

30. Guimet, E.; Diéguez, M.; Ruiz, A.; Claver, C. Asymmetric Hydrogenation of Prochiral Olefins Catalysed by Furanoside Thioether-Phosphinite Rh(I) and $\operatorname{Ir}(\mathrm{I})$ Complexes. Dalton Trans. 2005, 2557-2562.

31. Evans, D.A.; Michael, F.E.; Tedrow, J.S.; Campos, K.R. Application of Chiral Mixed Phosphorus/Sulfur Ligands to Enantioselective Rhodium-Catalyzed Dehydroamino Acid Hydrogenation and Ketone Hydrosilylation Processes. J. Am. Chem. Soc. 2003, 125, 3534-3543.

32. Hauptman, E.; Fagan, P.J.; Marshall, W. Synthesis of Novel (P,S) Ligands Based on Chiral Nonracemic Episulfides. Use in Asymmetric Hydrogenation. Organometallics 1999, 18, 2061-2073.

33. Dervisi, A.; Koursarou, D.; Ooi, L.; Horton, P.N.; Hursthouse, M.B. Synthesis and Characterization of Benzyl Phosphino-Thioether and -Thiolato Pd(II) Complexes and Their Applications in Suzuki Coupling Reactions. Dalton Trans. 2006, 5717-5724.

34. Huynh, H.V.; Han, Y.; Ho, J.H.H.; Tan, G.K. Palladium(II) Complexes of a Sterically Bulky, Benzannulated N-Heterocyclic Carbene with Unusual Intramolecular C-H $\cdots \mathrm{Pd}$ and $\mathrm{C}_{\text {carbene }} \cdots \mathrm{Br}$ Interactions and Their Catalytic Activities. Organometallics 2006, 25, 3267-3274.

35. Gu, S.; Xu, H.; Zhang, N.; Chen, W. Triazole-Functionalized N-Heterocyclic Carbene Complexes of Palladium and Platinum and Efficient Aqueous Suzuki-Miyaura Coupling Reaction. Chem. Asian J. 2010, 5, 1677-1686.

36. Bedford, R.B.; Blake, M.E.; Butts, C.P.; Holder, D. The Suzuki Coupling of Aryl Chlorides in TBAB-Water Mixtures. Chem. Commun. 2003, 466-467.

37. Türkmen, H.; Can, R.; Çetinkaya, B. Aqueous-Phase Suzuki-Miyaura Cross-Coupling Reactions Catalyzed by Pd-NHC Complexes. Dalton Trans. 2009, 7039-7044.

38. Rosner, T.; Bars, J.L.; Pfaltz, A.; Blackmond, D.G. Kinetic Studies of Heck Coupling Reactions Using Palladacycle Catalysts: Experimental and Kinetic Modeling of the Role of Dimer Species. $J$. Am. Chem. Soc. 2001, 123, 1848-1855. 
39. Huynh, H.V.; Ho, J.H.H.; Neo, T.C.; Koh, L.L. Solvent-Controlled Selective Synthesis of a trans-Configured Benzimidazolin-2-ylidene Palladium(II) Complex and Investigations of Its Heck-Type Catalytic Activity. J. Organomet. Chem. 2005, 690, 3854-3860.

40. Müller, T.E.; Hultzsch, K.C.; Yus, M.; Foubelo, F.; Tada, M. Hydroamination: Direct Addition of Amines to Alkenes and Alkynes. Chem. Rev. 2008, 108, 3795-3892.

41. Müller, T.E.; Beller, M. Metal-Initiated Amination of Alkenes and Alkynes. Chem. Rev. 1998, 98, 675-703.

42. Huynh, H.V.; Seow, H.X. Synthesis and Structural Characterization of Palladium Dicarbene Complexes Bearing Labile Co-Ligands. Aust. J. Chem. 2009, 62, 983-987.

43. Gischig, S.; Togni, A. Pd ${ }^{\mathrm{II}}$ Complexes of Tridentate PCP N-Heterocyclic Carbene Ligands: Structural Aspects and Application in Asymmetric Hydroamination of Cyano Olefins. Eur. J. Inorg. Chem. 2005, 4745-4754.

44. Dash, C.; Shaikh, M.M.; Butcher, R.J.; Ghosh, P. A Comparison between Nickel and Palladium Precatalysts of 1,2,4-Triazole Based $N$-Heterocyclic Carbenes in Hydroamination of Activated Olefins. Dalton Trans. 2010, 39, 2515-2524.

(C) 2012 by the authors; licensee MDPI, Basel, Switzerland. This article is an open access article distributed under the terms and conditions of the Creative Commons Attribution license (http://creativecommons.org/licenses/by/3.0/). 